\title{
Electron impact ionization of R-carvone: I. Mass spectra and appearance energies
}

\author{
M.C.A. Lopes ${ }^{\text {a, }}{ }^{*}$, W.A.D. Pires ${ }^{\text {a }}$, R.A.A. Amorim ${ }^{\text {a }}$, A.C.P. Fernandes ${ }^{\text {a }}$, T.M. Casagrande ${ }^{\text {a }}$, \\ D.B. Jones ${ }^{\text {b }}$, F. Blanco ${ }^{\text {c }}$, G. Garcia ${ }^{\text {d, }}$, M.J. Brunger ${ }^{\text {b, e }}$ \\ a Departamento de Física, Universidade Federal de Juiz de Fora, Juiz de Fora, MG, 36936-900, Brazil \\ b College of Science and Engineering, Flinders University, GPO Box 2100, Adelaide, SA, 5001, Australia \\ ${ }^{c}$ Departamento de Estructura de la Materia, Física Térmica y Electrónica e IPARCOS, Universidad Complutense de Madrid, 28040, Madrid, Spain \\ ${ }^{\mathrm{d}}$ Instituto de Física Fundamental, Consejo Superior de Investigaciones Científicas (CSIC), Serrano 113-bis, 28006, Madrid, Spain \\ e Dept of Actuarial Science and Applied Statistics, Faculty of Business and Information Science, UCSI University, Kuala Lumpur, 56000, Malaysia
}

\section{A R T I C L E I N F O}

\section{Article history:}

Received 22 June 2020

Received in revised form 13 July 2020

Accepted 15 July 2020

Available online 22 July 2020

\section{Keywords:}

Mass spectra

Direct ionization and dissociative ionization

Appearance energies

Herbal remedies

Biological actions

\begin{abstract}
A B S T R A C T
The mass spectrum of R-carvone measured at $70 \mathrm{eV}$ electron impact energy, in the mass region of $1-151$ amu, is reported in this work. We observed in this spectrum 103 peaks associated with ionic fragmentation, 55 of them with abundances greater than $1 \%$. The relative abundances, from this study, compare reasonably well with the corresponding values reported in the literature where such a comparison can be made. The R-carvone Ionization Energy (IE), as well as the ionic energy formation thresholds (Appearance Energy - AE) were experimentally determined for the 35 most intense cations registered in the mass spectrum, which provided values for 38 AEs and Wannier exponents $(p)$ and the IE of this molecule. The values of the AEs and Wannier exponents produced in this work, to the best of our knowledge, are being presented for the first time to the scientific community, except for the masses of $135 \mathrm{amu}$ and $150 \mathrm{amu}$. We also suggest some ionic fragmentation mechanisms and molecular structural ionic fragmentation mechanisms for R-carvone, based on the $\mathrm{AE}$ and $p$ values found in this work.
\end{abstract}

() 2020 Elsevier B.V. All rights reserved.

\section{Introduction}

The importance of the use of medicinal plants for the treatment of diseases is relevant and one of the characteristics of plants with multiple therapeutic properties is their essential oils, which have several biological actions, such as antibacterial, antifungal, antioxidant, cytotoxic and analgesic, among others. We can find in the literature several studies focusing on the active compounds present in essential oils, aiming to better understand their properties and applications [1-5].

To contribute to this research field, we report in this work our recent investigation on the organic molecule $\mathrm{R}$-carvone $\left(\mathrm{C}_{10} \mathrm{H}_{14} \mathrm{O}\right)$, which is the main active component present in essential mint oil (Mentha spicata L.). R-carvone has well-documented biological properties, including antimicrobial, fungicidal, anaesthetic, antinociceptive, anticonvulsant and antitumorigenic, sedative and antiinflammatory [6-11]. Due to its fungicidal property, it has been

\footnotetext{
* Corresponding author.

E-mail address: cristina.lopes@ufjf.edu.br (M.C.A. Lopes).
}

widely investigated for its ability to combat various types of fungi, such as Candida albicans, which is very common in the human body. This fungus may cause death due to the infections generated by it, especially in patients with weakened immune systems, such as those with AIDS, and also for patients undergoing some types of cancer treatment, such as chemotherapy [12].

When ionizing radiation interacts with a biological medium, such as the human body, low energy quasi-free electrons are produced on a large scale, which in turn can further collide with the medium generating even more secondary electrons. These secondary electrons can cause biological effects, depositing their energies through successive inelastic collisions with the biological molecules and/or by causing strand breaks in DNA and RNA and by bond dissociation in general [13]. The dynamics of these processes can only be understood and configured through a detailed qualitative and quantitative understanding of the fundamental interactions that occur. In this sense, fundamental studies on electron collisions with R-carvone may elucidate, in conjunction with charged-particle track simulations [14,15], the nanoscale behaviour of the pathway of secondary electrons in the human body, where 
this moiety is present, under the effects of radiation [14]. The qualitative aspects of these studies are related to which reaction channels may be activated, for example, which ionic fragments may be produced, while regarding the quantitative aspects, the determination of cross section (CS) values associated with each product formed, reflecting the reactivity of R-carvone to low energy electron impact, are crucial. These experimental CS values, when compared to any available theoretical results, may validate the reaction paradigm proposed in those studies, and then be subsequently employed to determine macroscopic quantities, such as particle range and energy deposition of electrons in the medium, in corresponding simulation modelling $[14,15]$. To understand quantitatively the interaction of incident radiation on R-carvone and its consequences, reliable databases of all of its cross sections are needed $[16,17]$. Furthermore, given that the current practice is to use only water to represent the biological media in the human body, as it makes up about $78 \%$ of the human body, is an approximation that is possibly not very accurate [15], extensive and reliable CS data for all our body constituent moieties is now recognized as being crucial $[16,17]$.

Although there is a wide spectrum of applications for R-carvone reported in the literature, there is still little published fundamental data on its properties. This is particularly true for its electron, positron or photon collision behaviour. Specifically, there are no absolute total cross section (TCS), total ionization cross section (TICS) or partial ionization cross section (PICS) data for electron, positron and photon scattering currently available. Castilho et al. (2014) [18] reported an electronic excitation and ionic dissociation study of Rcarvone, using synchrotron radiation associated with a time-of-flight technique. In their study, electron-ion coincidence (PEPICO) results below $(520 \mathrm{eV})$, at around (530-540 eV) and above (545 eV) the $\mathrm{O} 1 \mathrm{~s}$ edge were recorded. They also recorded the PEPICO spectrum before $(275 \mathrm{eV})$ and above the $\mathrm{C}$ 1s edge, and a valence ionization mass spectrum using a He I discharge lamp $(21.21 \mathrm{eV})$ for the sake of comparison. Garcia et al. (2003) [19] investigated the photoionization of R-carvone using low energy synchrotron radiation in the region from the ionization threshold (registered at $8.70 \pm 0.05 \mathrm{eV}$ ) up to $11 \mathrm{eV}$. They also reported and examined its threshold photoelectron spectra (TPES), to investigate the stability of the low-lying ionic states. The peak assignments in their threshold photoelectron spectra were made using Outer Valence Green's Function (OVGF) calculations, to identify the character of the outermost orbitals and to determine their ionization potentials. More recently, Jones et al. [20] reported an experimental and theoretical investigation into the dynamics of the electron-impact ionization of R-carvone. In that study, the experimental triple differential cross sections (TDCS) were obtained in asymmetric co-planar kinematic conditions, for the ionization of the unresolved combination of the three outermost molecular orbitals (41a-39a), while corresponding theoretical data were calculated within a molecular 3-body distorted wave (M3DW) framework.

In this paper we report original results for the relative mass spectrum (MS) of R-carvone, identifying the cationic fragments formed in the electron collision processes, and also determine, again for the first time, the appearance energies (AEs) and Wannier exponent $(p)$ values for the main cations observed.

\section{Apparatus and experimental method}

The MS of R-carvone was recorded in the mass region of 1-151 amu, with a resolution of $1 \mathrm{amu}$, using a HIDEN-EPIC 300 quadrupole mass spectrometer (QMS). Since this spectrometer and the precautions we took in making the measurements have been described in detail in our previous articles on ionization in the primary alcohols [21-24], here we will only summarize the aspects associated with handling and introducing the sample into the high vacuum chamber. Note that a couple of interesting papers $[25,26]$ looking at factors responsible for mass discrimination in quadrupole mass spectrometers, might also be consulted.

A 99.9\% pure R-carvone sample, commercially sold by Sigma Aldrich, was used. Prior to admitting the sample into the gas lines, and therefore into the vacuum chamber, that sample was put through a freeze pump procedure six times for further purification. The R-carvone sample was inserted into the high vacuum chamber by effusion through a $1 \mathrm{~mm}$ diameter molybdenum cannula, positioned perpendicularly to the EPIC 300 axis, and $10 \mathrm{~cm}$ below the electron source. R-carvone is a light champagne-coloured liquid, which is very difficult to work with. It has a low vapour pressure $\left(0.4 \mathrm{mmHg}\right.$ at $\left.20{ }^{\circ} \mathrm{C}\right)$, is hygroscopic, easily undergoes photolysis, and moreover adheres strongly to the inner walls of the apparatus. Due to its low vapour pressure, the high vacuum chamber was kept at $65{ }^{\circ} \mathrm{C}$, using heating tapes, thereby avoiding condensation on the internal surfaces of the apparatus. The external sample was kept at a constant temperature of $40^{\circ} \mathrm{C}$ during data acquisition, producing a working pressure of around $1 \times 10^{-6}$ Torr. The gas lines were also kept warm, at a temperature of around $50{ }^{\circ} \mathrm{C}$, to prevent R-carvone from being condensed on their surfaces. When R-carvone reacts with molecules from air, due to any leakage into the gas line, it becomes caramel coloured due to oxidation, making it necessary to discard that sample [27]. It is important to note that on some occasions, when trying to raise the sample pressure by heating it to a higher temperature, there was great instability in the working pressure, as well as severe contamination of the sealing rings present in our gas lines such as in the on/off valves. Indeed, under those circumstances the O-rings were damaged, resulting in gas line leaks and sample decomposition. Due to the low working pressure obtained, in this study we did not use a needle valve to control the sample admission to the vacuum chamber, keeping the valves of the gas lines fully open during the experiment. Nonetheless, in spite of all these challenges associated with using R-carvone, all the data reported in the next section were acquired under stable operating conditions. We are therefore confident that with our proven measurement techniques [24], the results we present are physical.

\section{Results and discussion}

\subsection{The mass spectrum}

The R-carvone MS shown in Fig. 1, provides data that helps us to understand how this molecule decomposes by giving the relative abundance of the cationic fragments generated as a result of dissociative ionization. This spectrum, measured at $70 \mathrm{eV}$ electron impact energy, was obtained by averaging a series of R-carvone MS recorded over several days and by subtracting the average of the residual gas signal recorded previously when no R-carvone was present in the chamber. The uncertainties in these data were calculated, in the usual manner, initially from the standard deviations associated with the averaged signal + background (SD1) and background (SD2) spectra, and subsequently by combining these standard deviations after the subtraction process (overall error $\left.=\left(S D 1^{2}+S D 2^{2}\right)^{0.5}\right)$. These overall uncertainties can be found in Table 1, where their value is seen to change for the different cations found. The intensity scale in this spectrum, including uncertainties, was subsequently normalized by attribution to the base peak (the most intense peak registered at $82 \mathrm{amu}$ ) the relative abundance of 100. In addition, the mass scale was calibrated to an absolute value, by recording a detailed mass spectrum with a mass step size variation of $0.01 \mathrm{amu}$, against the peak related to that for ionized water $\left(\mathrm{H}_{2} \mathrm{O}^{+}\right)$at $18 \mathrm{amu}$. This calibration typically required 


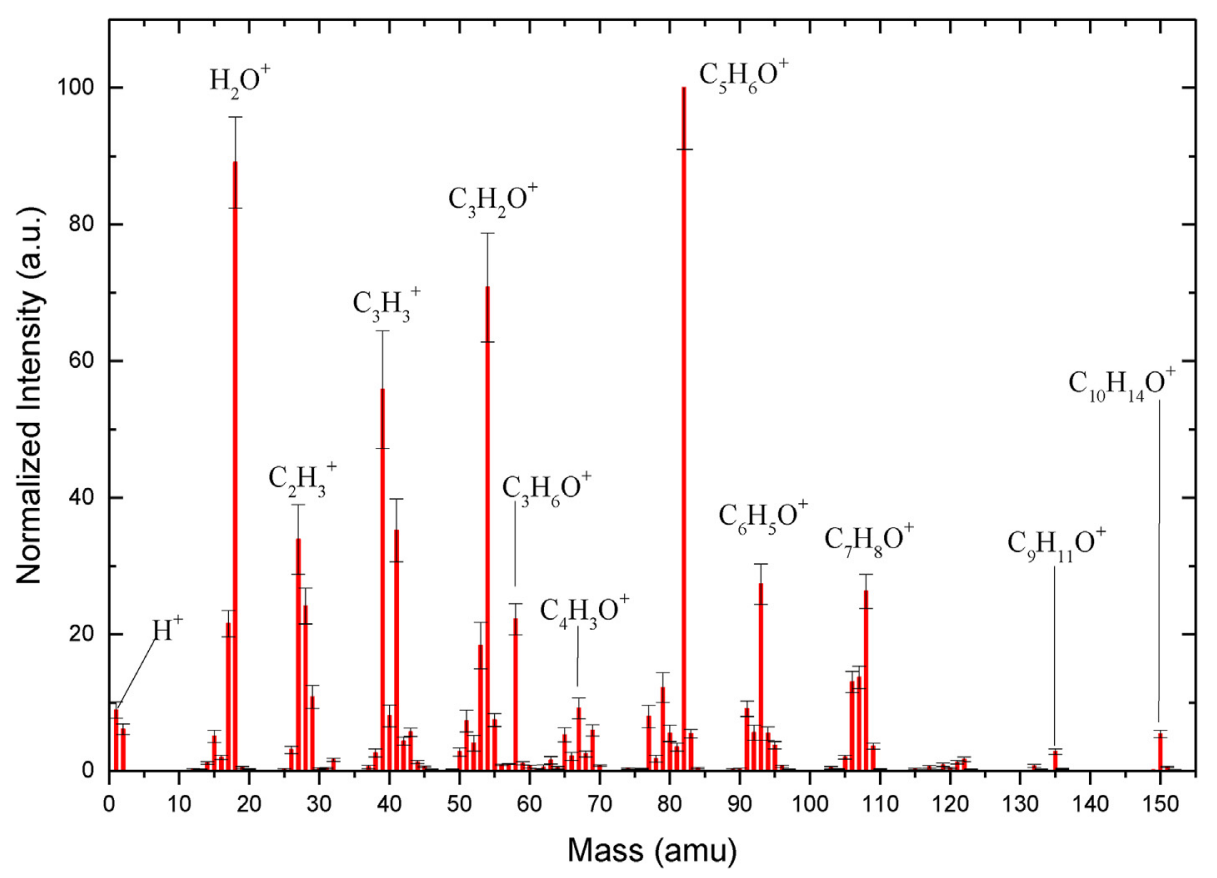

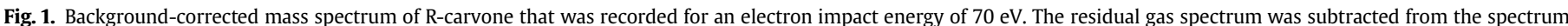

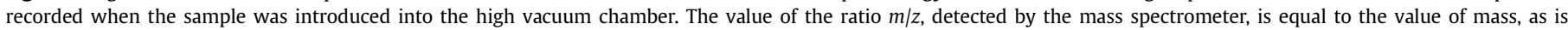
discussed in the text.

a correction in the mass scale of +0.2 amu. The highly hygroscopic profile of R-carvone was evident in our spectra, since the water peak recorded at 18 amu was always present and quite prominent in the region of masses lower than $20 \mathrm{amu}$.

The quantity of peaks observed in our spectrum (see Fig. 1) is much larger in number than those found using low-energy photon excitation, i.e. the He I PES reported by Castilho et al. [18] and using a synchrotron radiation source at $95 \mathrm{eV}$ photon energy as reported by Garcia et al. [19]. This seems to be a common characteristic, also apparent when R-carvone mass spectra obtained using these two (photon) excitation sources were compared amongst themselves [18]. Our spectrum also presents a much richer number of features than were observed in the previously reported studies using electron impact $[28,29]$, very probably due to the higher massresolution of our spectrometer. Another characteristic observed in Fig. 1 is that the base peak in the mass spectrum for electron impact was observed at $82 \mathrm{amu}$, due to the formation of the $\mathrm{C}_{5} \mathrm{H}_{6} \mathrm{O}^{+}$ion, while in the photo-fragmentation spectra $(21.21 \mathrm{eV}$ [18] and $95 \mathrm{eV}$ [ 19]), it corresponded to the parent cation $\left(\mathrm{M}^{+}\right)$observed at 150 amu. However, in the photo-fragmentation studies conducted by Castilho et al. [18], their base peak was also clearly observed at 82 amu and was attributed by them to the formation of the $\mathrm{C}_{5} \mathrm{H}_{6} \mathrm{O}^{+}$ ion. It should be noted that in the investigation carried out by Castilho et al. [18] the mass spectra were obtained using a time-offlight mass spectrometer and photon impact at significantly higher energies (275 and $310 \mathrm{eV}$ ) than used in this work, producing interaction mechanisms inaccessible to our studies, that is, core excitation processes, which may induce a much larger degree of fragmentation of the molecule. The result of this is a decrease in the relative intensity of the parent ion and other cations observed in low energy impact, as well as a higher degree of the molecule atomization.

The assignment for the peak identities observed in our R-carvone MS, their relative abundancy, associated uncertainties and residual gas background contributions are all presented in Table 1. Although the direct double ionization potential (IP) for organic molecules occurs in the range of 30-40 eV [31,32], and we have used $70 \mathrm{eV}$ electron impact to record our MS, in our assignments we considered that all the observed peaks were due to the formation of single-charged cations. This assumption was based on the fact that usually the cross sections for the formation of doubly-charged ions are, at least, an order of magnitude smaller than those for the formation of single-charged ions [23]. Furthermore, since the parent ion of R-carvone $\left(\mathrm{M}^{+}\right)$was observed at $150 \mathrm{amu}$, the peak, due to the formation of the doubly ionized R-carvone, would need to be observed at $75 \mathrm{amu}$. The $\mathrm{M}^{+}$species was observed with a relative abundance of 5.39, meaning that the double ionized cation $\mathrm{M}^{++}$ would typically have an abundance of about 0.54 . However, the peak observed at 75 amu presents an abundance of 0.21 . This is consistent with the abundances found for the series of $\mathrm{C}_{4} \mathrm{H}_{\mathrm{n}} \mathrm{O}^{+}$ cations, i.e. $\mathrm{C}_{4} \mathrm{H}_{10} \mathrm{O}^{+}$(at $74 \mathrm{amu}$, with abundance of $\sim 0.33$ ) and for $\mathrm{C}_{4} \mathrm{H}_{12} \mathrm{O}^{+}$(at $76 \mathrm{amu}$, with abundance of 0.31 ). This observation suggests that there was no contribution of the doubly charged ions $\left(\mathrm{C}_{10} \mathrm{H}_{14} \mathrm{O}^{++}\right)$to this $75 \mathrm{amu}$ peak, but it arose due only to the formation of the $\mathrm{C}_{4} \mathrm{H}_{11} \mathrm{O}^{+}$cation.

In our spectrum (Fig. 1) we observed 103 peaks associated with the ionic fragmentation process, 55 of which had normalized intensities (abundances) greater than 1\%. Among them there are 4 peaks (with masses of $18 \mathrm{amu}, 39 \mathrm{amu}, 54 \mathrm{amu}$ and the base peak at $82 \mathrm{amu}$ ) with abundances greater than $50 \%$. Disregarding the peak at mass $18 \mathrm{amu}$, formed due to the contribution of R-carvone ionic fragmentation and from singly ionized water from some sample contamination, the contribution of the 3 most prominent peaks, observed at $39 \mathrm{amu}, 54 \mathrm{amu}$ and at $82 \mathrm{amu}$, represent $40 \%$ of the total intensity observed in the mass spectrum. The present spectrum is essentially divided into 12 peak groups, with masses in the 1-2 amu, 12-20 amu, 24-32 amu, 36-48 amu, 49-61 amu, 62-70 amu, 73-84 amu, 89-96 amu, 102-110 amu, 115-123 amu, 130-137 amu and 148-151 amu ranges, respectively. In the mass group of 24-32 amu, the most prominent peak, of mass $27 \mathrm{amu}$, is associated with the formation of the $\mathrm{C}_{2} \mathrm{H}_{3}^{+}$cation, while in the mass group 36-48 amu the main peak is at 39 amu $\left(\mathrm{C}_{3} \mathrm{H}_{3}^{+}\right)$. Similarly, for 
Table 1

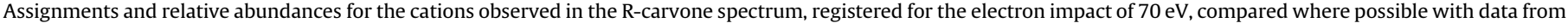

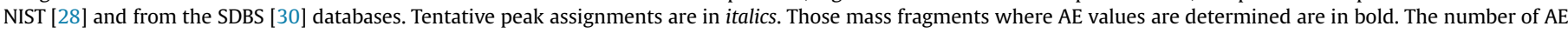

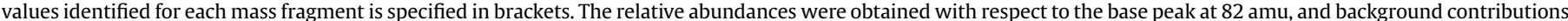

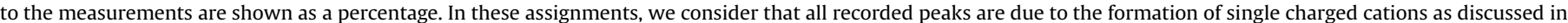
the text.

\begin{tabular}{|c|c|c|c|c|c|c|}
\hline \multirow[t]{2}{*}{ Cation Identity } & \multirow[t]{2}{*}{ m (a.m.u.) } & Present Data & \multirow[t]{2}{*}{ Error } & \multirow[t]{2}{*}{ Background \% } & \multirow[t]{2}{*}{ NIST [28] } & \multirow[t]{2}{*}{ SDBS [30] } \\
\hline & & Abundance & & & & \\
\hline $\mathrm{H}^{+}$ & 1 & 8.91 & 1.22 & 12.17 & & \\
\hline $\mathrm{H}_{2}^{+}$ & 2 & 6.08 & 0.77 & 3.44 & & \\
\hline $\mathrm{C}^{+}$ & 12 & 0.21 & 0.12 & 4.18 & & \\
\hline $\mathrm{CH}^{+}$ & 13 & 0.14 & 0.10 & 7.56 & & \\
\hline $\mathrm{CH}_{2}^{+}$ & $14(1 \mathrm{AE})$ & 1.16 & 0.19 & 6.27 & 0.80 & \\
\hline $\mathrm{CH}_{3}^{+}$ & 15 & 5.05 & 0.89 & 3.57 & & \\
\hline $\mathrm{O}^{+}$ & $16(1 \mathrm{AE})$ & 1.96 & 0.36 & 7.00 & & \\
\hline $\mathrm{HO}^{+}$ & 17 & 21.57 & 1.91 & 10.00 & & \\
\hline $\mathrm{H}_{2} \mathrm{O}^{+}$ & 18 & 89.06 & 6.68 & 10.19 & & \\
\hline $\mathrm{H}_{3} \mathrm{O}^{+}$ & 19 & 0.51 & 0.15 & 5.29 & & \\
\hline $\mathrm{H}_{2} \mathrm{DO}^{+}$ & 20 & 0.24 & 0.08 & 7.57 & & \\
\hline $\mathrm{C}_{2}^{+}$ & 24 & 0.04 & 0.04 & 4.85 & & \\
\hline $\mathrm{C}_{2} \mathrm{H}^{+}$ & 25 & 0.20 & 0.11 & 5.04 & & \\
\hline $\mathrm{C}_{2} \mathrm{H}_{2}^{+}$ & $26(1 \mathrm{AE})$ & 3.08 & 0.53 & 2.28 & 0.90 & 1.0 \\
\hline $\mathrm{C}_{2} \mathrm{H}_{3}^{+}$ & 27 & 33.89 & 5.14 & 1.50 & 8.15 & 11.3 \\
\hline $\mathrm{C}_{2} \mathrm{H}_{4}^{+}, \mathrm{CO}^{+}$ & $28(2 \mathrm{AE})$ & 24.12 & 2.61 & 4.53 & 0.59 & 2.0 \\
\hline $\mathrm{C}_{2} \mathrm{H}_{5}^{+}, \mathrm{CHO}^{+}$ & $29(2 \mathrm{AE})$ & 10.82 & 1.65 & 10.21 & 2.03 & 3.3 \\
\hline $\mathrm{CH}_{2} \mathrm{O}^{+}$ & 30 & 0.34 & 0.13 & 13.00 & & \\
\hline $\mathrm{CH}_{3} \mathrm{O}^{+}$ & $31(1 \mathrm{AE})$ & 0.40 & 0.08 & 8.48 & & \\
\hline $\mathrm{CH}_{4} \mathrm{O}^{+}$ & 32 & 1.62 & 0.21 & 10.97 & & \\
\hline $\mathrm{C}_{3}^{+}$ & 36 & 0.08 & 0.05 & 5.97 & & \\
\hline $\mathrm{C}_{3} \mathrm{H}^{+}$ & 37 & 0.58 & 0.23 & 2.99 & & \\
\hline $\mathrm{C}_{3} \mathrm{H}_{2}^{+}$ & 38 & 2.62 & 0.57 & 1.19 & & 1.7 \\
\hline $\mathrm{C}_{3} \mathrm{H}_{3}^{+}$(2 isomers) & $39(2 \mathrm{AE})$ & 55.82 & 8.63 & 0.67 & 31.87 & 24.9 \\
\hline $\mathrm{C}_{3} \mathrm{H}_{4}^{+}$ & $40(1 \mathrm{AE})$ & 8.04 & 1.62 & 1.07 & 5.53 & 4.2 \\
\hline $\mathrm{C}_{3} \mathrm{H}_{5}^{+}, \mathrm{C}_{2} \mathrm{HO}^{+}$ & $41(2 \mathrm{AE})$ & 35.23 & 4.62 & 5.80 & 17.50 & 18.5 \\
\hline $\mathrm{C}_{2} \mathrm{H}_{2} \mathrm{O}^{+}$ & $42(1 \mathrm{AE})$ & 4.34 & 0.57 & 10.15 & 2.83 & 1.4 \\
\hline $\mathrm{C}_{2} \mathrm{H}_{3} \mathrm{O}^{+}$ & $43(1 \mathrm{AE})$ & 5.65 & 0.61 & 36.91 & 1.84 & 1.4 \\
\hline $\mathrm{C}_{2} \mathrm{H}_{4} \mathrm{O}^{+}$ & 44 & 1.31 & 0.20 & 12.78 & & \\
\hline $\mathrm{C}_{2} \mathrm{H}_{5} \mathrm{O}^{+}$ & $45(1 \mathrm{AE})$ & 0.57 & 0.13 & 17.13 & & \\
\hline $\mathrm{C}_{2} \mathrm{H}_{6} \mathrm{O}^{+}$ & 46 & 0.21 & 0.06 & 14.83 & & \\
\hline $\mathrm{C}_{2} \mathrm{H}_{7} \mathrm{O}^{+}$ & 47 & 0.04 & 0.03 & 18.36 & & \\
\hline $\mathrm{C}_{4}^{+}$ & 48 & 0.03 & 0.02 & 8.85 & & \\
\hline $\mathrm{C}_{4} \mathrm{H}^{+}$ & 49 & 0.11 & 0.12 & 3.86 & & \\
\hline $\mathrm{C}_{4} \mathrm{H}_{2}^{+}$ & 50 & 2.77 & 0.60 & 2.11 & 4.10 & 2.2 \\
\hline $\mathrm{C}_{4} \mathrm{H}_{3}^{+}$ & 51 & 7.32 & 1.59 & 0.81 & 8.94 & 4.7 \\
\hline $\mathrm{C}_{4} \mathrm{H}_{4}^{+}$ & $52(1 \mathrm{AE})$ & 4.06 & 1.14 & 0.65 & 5.06 & 2.8 \\
\hline $\mathrm{C}_{4} \mathrm{H}_{5}^{+}$ & $53(1 \mathrm{AE})$ & 18.38 & 3.40 & 0.69 & 20.31 & 13.4 \\
\hline $\mathrm{C}_{4} \mathrm{H}_{6}^{+}$ & $54(1 \mathrm{AE})$ & 70.77 & 7.96 & 0.38 & 45.70 & 47.6 \\
\hline $\mathrm{C}_{4} \mathrm{H}_{7}^{+}$ & $55(1 \mathrm{AE})$ & 7.47 & 0.95 & 16.98 & 5.75 & 4.4 \\
\hline $\mathrm{C}_{4} \mathrm{H}_{8}^{+}, \mathrm{C}_{3} \mathrm{H}_{4} \mathrm{O}^{+}$ & 56 & 0.83 & 0.09 & 44.50 & & \\
\hline $\mathrm{C}_{3} \mathrm{H}_{6} \mathrm{O}^{+}$ & $58(1 \mathrm{AE})$ & 22.22 & 2.27 & 0.92 & 7.67 & 7.6 \\
\hline $\mathrm{C}_{3} \mathrm{H}_{7} \mathrm{O}^{+}$ & 59 & 1.10 & 0.24 & 2.39 & & \\
\hline $\mathrm{C}_{3} \mathrm{H}_{8} \mathrm{O}^{+}$ & $60(1 \mathrm{AE})$ & 0.63 & 0.22 & 3.73 & & \\
\hline $\mathrm{C}_{3} \mathrm{H}_{9} \mathrm{O}^{+}$ & 61 & 0.25 & 0.10 & 4.27 & & \\
\hline $\mathrm{C}_{5} \mathrm{H}_{2}^{+}$ & 62 & 0.52 & 0.35 & 1.32 & 1.16 & \\
\hline $\mathrm{C}_{5} \mathrm{H}_{3}^{+}$ & 63 & 1.56 & 0.54 & 1.07 & 2.98 & 1.4 \\
\hline $\mathrm{C}_{5} \mathrm{H}_{4}^{+}$ & 64 & 0.44 & 0.16 & 1.90 & 0.89 & \\
\hline $\mathrm{C}_{5} \mathrm{H}_{5}^{+}$ & $65(1 \mathrm{AE})$ & 5.26 & 1.06 & 1.78 & 7.35 & 3.8 \\
\hline $\mathrm{C}_{5} \mathrm{H}_{6}^{+}$ & 66 & 2.12 & 0.59 & 1.16 & 2.91 & 1.9 \\
\hline $\mathrm{C}_{5} \mathrm{H}_{7}^{+}$ & $67(1 \mathrm{AE})$ & 9.16 & 1.51 & 2.20 & 9.41 & 7.9 \\
\hline $\mathrm{C}_{5} \mathrm{H}_{8}^{+}$ & 68 & 2.48 & 0.44 & 5.06 & 2.48 & 2.3 \\
\hline $\mathrm{C}_{5} \mathrm{H}_{9}^{+}$ & $69(1 \mathrm{AE})$ & 5.95 & 0.84 & 14.90 & 3.48 & 3.5 \\
\hline $\mathrm{C}_{4} \mathrm{H}_{6} \mathrm{O}^{+}$ & 70 & 0.81 & 0.08 & 53.31 & & \\
\hline $\mathrm{C}_{4} \mathrm{H}_{9} \mathrm{O}^{+}$ & 73 & 0.09 & 0.03 & 36.36 & & \\
\hline $\mathrm{C}_{4} \mathrm{H}_{10} \mathrm{O}^{+}$ & 74 & 0.33 & 0.11 & 5.78 & & \\
\hline $\mathrm{C}_{4} \mathrm{H}_{11} \mathrm{O}^{+}$ & 75 & 0.21 & 0.08 & 8.61 & & \\
\hline $\mathrm{C}_{6} \mathrm{H}_{4}^{+}$ & 76 & 0.31 & 0.06 & 28.55 & & \\
\hline $\mathrm{C}_{6} \mathrm{H}_{5}^{+}$ & $77(1 \mathrm{AE})$ & 7.96 & 1.66 & 1.27 & 12.73 & 6.7 \\
\hline $\mathrm{C}_{6} \mathrm{H}_{6}^{+}$ & 78 & 1.76 & 0.53 & 1.51 & 3.62 & 1.9 \\
\hline $\mathrm{C}_{6} \mathrm{H}_{7}^{+}$ & $79(1 \mathrm{AE})$ & 12.21 & 2.20 & 0.62 & 16.61 & 10.8 \\
\hline $\mathrm{C}_{5} \mathrm{H}_{4} \mathrm{O}^{+}$ & $80(1 \mathrm{AE})$ & 5.48 & 1.18 & 0.56 & 6.02 & 5.5 \\
\hline $\mathrm{C}_{5} \mathrm{H}_{5} \mathrm{O}^{+}$ & 81 & 3.49 & 0.56 & 4.30 & 0.89 & 3.1 \\
\hline $\mathrm{C}_{5} \mathrm{H}_{6} \mathrm{O}^{+}$ & $82(1 \mathrm{AE})$ & 100.00 & 8.98 & 0.40 & 100.00 & 100.0 \\
\hline $\mathrm{C}_{5} \mathrm{H}_{7} \mathrm{O}^{+}$ & $83(1 \mathrm{AE})$ & 5.45 & 0.63 & 9.14 & 5.08 & 5.6 \\
\hline $\mathrm{C}_{5} \mathrm{H}_{8} \mathrm{O}^{+}$ & 84 & 0.43 & 0.07 & 45.54 & & \\
\hline $\mathrm{C}_{7} \mathrm{H}_{5}^{+}$ & 89 & 0.23 & 0.08 & 10.24 & & \\
\hline $\mathrm{C}_{7} \mathrm{H}_{6}^{+}$ & 90 & 0.27 & 0.13 & 3.23 & & \\
\hline $\mathrm{C}_{7} \mathrm{H}_{7}^{+}$or $\mathrm{C}_{6} \mathrm{H}_{3} \mathrm{O}^{+}$ & $91(1 \mathrm{AE})$ & 9.08 & 1.14 & 1.11 & 14.86 & 8.8 \\
\hline
\end{tabular}


Table 1 (continued)

\begin{tabular}{|c|c|c|c|c|c|c|}
\hline \multirow[t]{2}{*}{ Cation Identity } & \multirow[t]{2}{*}{ m (a.m.u.) } & Present Data & \multirow[t]{2}{*}{ Error } & \multirow[t]{2}{*}{ Background \% } & \multirow[t]{2}{*}{ NIST [28] } & \multirow[t]{2}{*}{ SDBS $[30]$} \\
\hline & & Abundance & & & & \\
\hline $\mathrm{C}_{7} \mathrm{H}_{8}^{+}$or $\mathrm{C}_{6} \mathrm{H}_{4} \mathrm{O}^{+}$ & $92(1 \mathrm{AE})$ & 5.60 & 1.09 & 0.56 & 6.55 & 4.9 \\
\hline $\mathrm{C}_{6} \mathrm{H}_{5} \mathrm{O}^{+}$ & $93(1 \mathrm{AE})$ & 27.33 & 2.98 & 0.59 & 31.27 & 26.5 \\
\hline $\mathrm{C}_{6} \mathrm{H}_{6} \mathrm{O}^{+}$ & $94(1 \mathrm{AE})$ & 5.47 & 0.99 & 1.50 & 6.64 & 6.0 \\
\hline $\mathrm{C}_{6} \mathrm{H}_{7} \mathrm{O}^{+}$ & 95 & 3.76 & 0.53 & 3.12 & 3.45 & 3.3 \\
\hline $\mathrm{C}_{7} \mathrm{H}_{12}^{+}$ & 96 & 0.68 & 0.16 & 13.38 & & \\
\hline $\mathrm{C}_{8} \mathrm{H}_{6}^{+}$ & 102 & 0.06 & 0.03 & 11.80 & & \\
\hline $\mathrm{C}_{8} \mathrm{H}_{7}^{+}$ & 103 & 0.44 & 0.17 & 4.16 & 1.02 & \\
\hline $\mathrm{C}_{8} \mathrm{H}_{8}^{+}$ & 104 & 0.29 & 0.05 & 31.16 & & \\
\hline $\mathrm{C}_{8} \mathrm{H}_{9}^{+}, \mathrm{C}_{7} \mathrm{H}_{5} \mathrm{O}^{+}$ & 105 & 2.02 & 0.30 & 6.02 & 4.30 & 2.4 \\
\hline $\mathrm{C}_{7} \mathrm{H}_{6} \mathrm{O}^{+}$ & $106(1 \mathrm{AE})$ & 13.02 & 1.55 & 0.48 & 12.70 & 11.4 \\
\hline $\mathrm{C}_{7} \mathrm{H}_{7} \mathrm{O}^{+}$ & $107(1 \mathrm{AE})$ & 13.68 & 1.64 & 0.69 & 19.08 & 16.8 \\
\hline $\mathrm{C}_{7} \mathrm{H}_{8} \mathrm{O}^{+}$ & $108(1 \mathrm{AE})$ & 26.29 & 2.47 & 0.56 & 25.86 & 31.9 \\
\hline $\mathrm{C}_{7} \mathrm{H}_{9} \mathrm{O}^{+}$ & 109 & 3.60 & 0.44 & 2.06 & 3.45 & 4.2 \\
\hline $\mathrm{C}_{7} \mathrm{H}_{10} \mathrm{O}^{+}$ & 110 & 0.27 & 0.05 & 15.93 & & \\
\hline $\mathrm{C}_{9} \mathrm{H}_{7}^{+}, \mathrm{C}_{8} \mathrm{H}_{3} \mathrm{O}^{+}$ & 115 & 0.29 & 0.10 & 9.95 & 1.35 & \\
\hline $\mathrm{C}_{9} \mathrm{H}_{8}^{+}, \mathrm{C}_{8} \mathrm{H}_{4} \mathrm{O}^{+}$ & 116 & 0.14 & 0.04 & 8.47 & & \\
\hline $\mathrm{C}_{9} \mathrm{H}_{9}^{+}, \mathrm{C}_{8} \mathrm{H}_{5} \mathrm{O}^{+}$ & 117 & 0.56 & 0.18 & 3.19 & 1.14 & \\
\hline $\mathrm{C}_{9} \mathrm{H}_{10}^{+}, \mathrm{C}_{8} \mathrm{H}_{6} \mathrm{O}^{+}$ & 118 & 0.12 & 0.04 & 9.31 & & \\
\hline $\mathrm{C}_{9} \mathrm{H}_{11}^{+}, \mathrm{C}_{8} \mathrm{H}_{7} \mathrm{O}^{+}$ & 119 & 0.88 & 0.24 & 6.03 & 1.06 & 1.0 \\
\hline $\mathrm{C}_{9} \mathrm{H}_{12}^{+}, \mathrm{C}_{8} \mathrm{H}_{8} \mathrm{O}^{+}$ & 120 & 0.40 & 0.09 & 6.73 & & \\
\hline $\mathrm{C}_{9} \mathrm{H}_{13}^{+}, \mathrm{C}_{8} \mathrm{H}_{9} \mathrm{O}^{+}$ & 121 & 1.27 & 0.23 & 6.80 & 1.62 & 1.6 \\
\hline $\mathrm{C}_{9} \mathrm{H}_{14}^{+}, \mathrm{C}_{8} \mathrm{H}_{10} \mathrm{O}^{+}$ & 122 & 1.67 & 0.34 & 3.60 & 1.96 & 1.9 \\
\hline $\mathrm{C}_{8} \mathrm{H}_{11} \mathrm{O}^{+}$ & 123 & 0.20 & 0.05 & 28.62 & & \\
\hline $\mathrm{C}_{10} \mathrm{H}_{10}^{+}$ & 130 & 0.03 & 0.02 & 27.79 & & \\
\hline $\mathrm{C}_{10} \mathrm{H}_{11}^{+}$ & 131 & 0.09 & 0.05 & 17.88 & & \\
\hline $\mathrm{C}_{10} \mathrm{H}_{12}^{+}$ & 132 & 0.72 & 0.22 & 5.41 & 0.87 & \\
\hline $\mathrm{C}_{10} \mathrm{H}_{13}^{+}, \mathrm{C}_{9} \mathrm{H}_{9} \mathrm{O}^{+}$ & 133 & 0.20 & 0.06 & 16.06 & 0.92 & \\
\hline $\mathrm{C}_{10} \mathrm{H}_{14}^{+}, \mathrm{C}_{9} \mathrm{H}_{10} \mathrm{O}^{+}$ & 134 & 0.06 & 0.02 & 23.08 & & \\
\hline $\mathrm{C}_{9} \mathrm{H}_{11} \mathrm{O}^{+}$ & $135(1 \mathrm{AE})$ & 2.81 & 0.39 & 4.28 & 8.21 & 3.3 \\
\hline $\mathrm{C}_{9} \mathrm{H}_{12} \mathrm{O}^{+}$ & 136 & 0.29 & 0.07 & 8.14 & 0.76 & \\
\hline $\mathrm{C}_{9} \mathrm{H}_{13} \mathrm{O}^{+}$ & 137 & 0.04 & 0.02 & 43.78 & & \\
\hline $\mathrm{C}_{10} \mathrm{H}_{12} \mathrm{O}^{+}$ & 148 & 0.05 & 0.02 & 48.89 & 1.12 & \\
\hline $\mathrm{C}_{10} \mathrm{H}_{14} \mathrm{O}^{+}$ & $150(1 \mathrm{AE})$ & 5.39 & 0.52 & 6.13 & 7.91 & 6.5 \\
\hline${ }^{12} \mathrm{C}_{9}^{13} \mathrm{CH}_{14} \mathrm{O}^{+}$ & 151 & 0.55 & 0.12 & 10.43 & 0.92 & \\
\hline
\end{tabular}

the mass group $49-61$ amu the largest peak is at 54 amu $\left(\mathrm{C}_{4} \mathrm{H}_{6}^{+}\right)$ and in the mass group 73-84 amu we find the base peak at $82 \mathrm{amu}$ $\left(\mathrm{C}_{5} \mathrm{H}_{6} \mathrm{O}^{+}\right)$. The abundances registered in our spectrum typically compare quite well with the data reported in the literature from NIST [28,29], with just a few exceptions [30]. The most pronounced discrepancies are observed for only 11 of the 55 masses reported by NIST [28] (that is, for 27 amu, 28 amu, 29 amu, 39 amu, 41 amu, 54 amu, $58 \mathrm{amu}, 91 \mathrm{amu}, 107 \mathrm{amu}, 135 \mathrm{amu}$ and $150 \mathrm{amu}$ ), with the maximum discrepancy being at $\mathrm{m}=27 \mathrm{amu}$. At $\mathrm{m}=27 \mathrm{amu}$ we find that NIST's value is $24 \%$ lower than that registered in our spectrum. However, for all the other 44 masses that we can compare against the NIST results [28], considering the error bars, good agreement was found. Table 1 also presents the data reported by the SDBS database [30]. However, there is a considerable difference in the abundances observed in our mass spectrum compared to the SDBS data [30], for example for the masses of 41 amu and $58 \mathrm{amu}$. These differences may be due to the high temperature $\left(180^{\circ} \mathrm{C}\right)$ of the sample of R-carvone used in the acquisition of the SDBS mass spectrum, which apparently favoured the formation of different cations.

The large number of peaks observed in the R-carvone MS makes its interpretation very difficult, considering that the formation of each cation may occur either by direct or indirect mechanisms, involving successive fragmentations and possibly rearrangements. Furthermore, in many regions of the spectrum, the assignment of the peaks to the formed cations cannot be determined uniquely from the $m / z$ ratios, since their masses can be attributed to different fragments, as can be seen in Table 1. The following possibilities must be considered in their assignment: i) The same mass can be due to different cations, which occurs for example for the peak at 41 amu, resulting from the contribution of the formation of the two cations $\mathrm{C}_{3} \mathrm{H}_{5}^{+}$and $\mathrm{C}_{2} \mathrm{HO}^{+}$, as suggested from our $\mathrm{AE}$ determinations that will be discussed in the next section; ii) The same cation can be produced through different dissociative mechanisms, resulting in two AE values; iii) It was also possible to observe two AE values due to the formation of isomeric species of the same cation, which was observed, for example, for the $\mathrm{C}_{3} \mathrm{H}_{3}^{+}$cation at $\mathrm{m}=39 \mathrm{amu}$; iv) For peaks with low abundance intensity, such as in the mass range of 115-122 amu of our mass spectrum, it was difficult to reach a reliable determination of their AEs, which could have helped the interpretation of the MS in that mass region. A solid assignment of these latter peaks to the formed cations, would be possible only through new information such as produced by other experimental techniques or high-level theoretical calculations.

We present below an analysis for the assignment of the peaks observed in the R-carvone MS listed in Table 1, starting with the formation of cations with higher masses. This is followed sequentially for those of smaller masses. In this Table the masses in bold are those in which we determined the AEs, and so it was possible to make a more conclusive peak assignment for them in the MS. On the other hand, some tentative assignments are in italics which only suggest the possible cations that may be formed for a specific mass. Note that the formation of cations which may have minimally contributed to the peaks observed in our MS (Fig. 1) were not included in Table 1. The parent cation $\left(\mathrm{M}^{+}\right)$of R-carvone $\left(\mathrm{C}_{10} \mathrm{H}_{14} \mathrm{O}^{+}\right)$, observed at 150 amu with a relatively low intensity, is generated by removing a bound electron from the oxygen atom [19]. A peak at 151 amu was also observed, with an intensity of $0.98 \%$ of the parent cation ( $150 \mathrm{amu}$ ), due to the formation of the ${ }^{12} \mathrm{C}_{9}^{13} \mathrm{CH}_{14} \mathrm{O}^{+}$cation, is consistent with the natural abundance of the ${ }^{13} \mathrm{C}$ isotope. 
We observe in this spectrum that the sequential loss of $\mathrm{H}$-atoms from a given initial cation, may generate a sequence of new cations, as we have listed immediately below. The group of peaks which conform to this behaviour have masses:

133 - 136 amu $\left(\mathrm{C}_{9} \mathrm{H}_{n} \mathrm{O}^{+}, n=9\right.$ to 12$)$ arise from the sequential loss of a $\mathrm{H}$ atom from $\mathrm{C}_{9} \mathrm{H}_{13} \mathrm{O}^{+}$(observed at $\mathrm{m}=137 \mathrm{amu}$ ), which formed due to the loss of a methylidyne radical $(\mathrm{CH})$ from $\mathrm{M}$;

$130-133$ amu $\left(C_{10} H_{n}^{+}, n=8,10\right.$ to 13$)$ arise from the $\mathrm{C}_{10} \mathrm{H}_{14}^{+}$cation, which was formed by the removal of an $\mathrm{O}$-atom from $\mathrm{M}$;

115 - 123 amu $\left(\mathrm{C}_{8} \mathrm{H}_{n} \mathrm{O}^{+}, n=3\right.$ to 10$)$ arise from the $\mathrm{C}_{8} \mathrm{H}_{11} \mathrm{O}^{+}$ cation, formed due to the loss of a $\mathrm{C}_{2} \mathrm{H}_{3}$ moiety from $\mathrm{M}$;

$115-122$ amu $\left(C_{9} H_{n}^{+}, n=7\right.$ to 13$)$ which come from the $\mathrm{C}_{9} \mathrm{H}_{14}^{+}$ cation.

$105-110 \mathrm{amu}\left(\mathrm{C}_{7} \mathrm{H}_{n} \mathrm{O}^{+}, n=5\right.$ to 9$)$ which may come from the $\mathrm{C}_{7} \mathrm{H}_{10} \mathrm{O}^{+}$cation. Castilho et al. [18] proposed another mechanism to form the $\mathrm{C}_{7} \mathrm{H}_{8} \mathrm{O}^{+}$ion (at $108 \mathrm{amu}$ ), due the breakage of the isopropenyl moiety $\left(\mathrm{C}_{3} \mathrm{H}_{5}\right)$ from $\mathrm{M}$, followed by the loss of the methyl $\mathrm{CH}_{3}$ radical $(\mathrm{m}=15 \mathrm{amu})$ together with a $\mathrm{C}_{6} \mathrm{H}_{5} \mathrm{O}^{+}$cation $(\mathrm{m}=93$ amu);

$102-105$ amu $\left(C_{8} H_{n}^{+}, n=6\right.$ to 8$)$ which come from the $\mathrm{C}_{8} \mathrm{H}_{9}^{+}$ cation;

91 - 95 amu $\left(\mathrm{C}_{6} \mathrm{H}_{n} \mathrm{O}^{+}, n=3\right.$ to 6$)$ which come from the $\mathrm{C}_{6} \mathrm{H}_{7} \mathrm{O}^{+}$ cation, and which may arise due to the breakage of the isopropenyl $\left(\mathrm{C}_{3} \mathrm{H}_{5}\right)$ and methyl $\left(\mathrm{CH}_{3}\right)$ moieties from $\mathrm{M}$.

89 - 92 amu $\left(C_{7} H_{n}^{+}, n=5\right.$ to 7$)$ which come from the $\mathrm{C}_{7} \mathrm{H}_{8}^{+}$cation;

$80-84 \mathrm{amu}\left(\mathrm{C}_{5} \mathrm{H}_{n} \mathrm{O}^{+}, n=4\right.$ to 7$)$ which come from the $\mathrm{C}_{5} \mathrm{H}_{8} \mathrm{O}^{+}$ cation. Note that the base peak observed at $82 \mathrm{amu}$, in addition to its formation due to the sequential loss of $\mathrm{H}$-atoms from $\mathrm{C}_{5} \mathrm{H}_{8} \mathrm{O}^{+}$as described here, may also have a formation route from a retro DielsAlder reaction from $\mathrm{M}$ [18]. This pathway was proposed by Castilho et al. [18] and will be discussed further in the following section;

$76-79$ amu $\left(C_{6} H_{n}^{+}, n=6\right.$ to 4$)$ which come from the $\mathrm{C}_{6} \mathrm{H}_{7}^{+}$ cation;

70 - 75 amu $\left(C_{4} \mathrm{H}_{n} \mathrm{O}^{+}, n=6,9,10\right)$ which come from the $\mathrm{C}_{4} \mathrm{H}_{11} \mathrm{O}^{+}$ cation;

62 - 69 amu $\left(C_{5} H_{n}^{+}, n=2\right.$ to 8$)$ which come from the $\mathrm{C}_{5} \mathrm{H}_{9}^{+}$cation; 56 - $61 \mathrm{amu}\left(\mathrm{C}_{3} \mathrm{H}_{n} \mathrm{O}^{+}, n=4,6\right.$ to 8$)$ which come from the $\mathrm{C}_{3} \mathrm{H}_{9} \mathrm{O}^{+}$ cation;

$48-56$ amu $\left(C_{4} H_{n}^{+}, n=1\right.$ to 7 and $\left.C_{4}^{+}\right)$which come from the $\mathrm{C}_{4} \mathrm{H}_{8}^{+}$ cation. In addition to the formation of these cations by the sequence loss of the $\mathrm{H}$-atom, Castilho et al. [18] proposed a pathway for $\mathrm{C}_{4} \mathrm{H}_{6}^{+}$ fragmentation, involving the production of a methyl radical $(\mathrm{m}=15$ amu) and a $\mathrm{C}_{3} \mathrm{H}_{3}$ moiety, which in turn, loses a $\mathrm{C}$ atom producing a $\mathrm{C}_{2} \mathrm{H}_{3}$ radical $(\mathrm{m}=27 \mathrm{amu})$;

41 - 47 amu $\left(\mathrm{C}_{2} \mathrm{H}_{n} \mathrm{O}^{+}, n=1\right.$ to 6$)$ which come from the ethyloxonium cation $\left(\mathrm{C}_{2} \mathrm{H}_{7} \mathrm{O}^{+}\right)$;

36 - $41 \mathrm{amu}\left(\mathrm{C}_{3}^{+}\right.$and $\mathrm{C}_{3} \mathrm{H}_{n}^{+}, n=1$ to 4 ) which come from the $\mathrm{C}_{3} \mathrm{H}_{5}^{+}$ cation. Between these different cations, additional isomeric species may be produced as we have observed for the $\mathrm{C}_{3} \mathrm{H}_{3}^{+}$cation;

28-36 amu ( $\mathrm{CO}^{+}$and $\mathrm{CH}_{\mathrm{n}} \mathrm{O}^{+}, \mathrm{n}=1$ to 3 ) which come from the $\mathrm{CH}_{4} \mathrm{O}^{+}$cation;

24-29 amu ( $\mathrm{C}_{2}^{+}$and $\mathrm{C}_{2} \mathrm{H}_{\mathrm{n}}^{+}, \mathrm{n}=1$ to 5$)$ which come from the $\mathrm{C}_{2} \mathrm{H}_{6}^{+}$ cation.

The peaks observed for masses 20 amu and 19 amu originate from the formation of the hydronium ions, $\mathrm{H}_{2} \mathrm{DO}^{+}, \mathrm{H}_{3} \mathrm{O}^{+}$, and are caused by protonation, i.e., the interaction of $\mathrm{H}_{2} \mathrm{O}$ (or $\mathrm{H}_{2} \mathrm{DO}$ ) with one proton $\mathrm{H}^{+}$. In addition, the masses 18 amu and 17 amu came from the formation of the $\mathrm{H}_{2} \mathrm{O}^{+}$and $\mathrm{HO}^{+}$cations. Note that the abundancies of the $\mathrm{H}_{2} \mathrm{O}^{+}$ and the $\mathrm{HO}^{+}$cations are rather high, very probably due to minor contamination of the R-carvone sample with water in the gas lines or the supplied sample, suggesting that the intensity of these peaks is due, not only to R-carvone ionic fragmentation [18], but also to $\mathrm{H}_{2} \mathrm{O}$ ionization and fragmentation. We also observed the formation of $\mathrm{O}^{+}$, in reasonable accord with the abundances registered for the $\mathrm{C}_{10} \mathrm{H}_{\mathrm{n}}^{+}$
Table 2

Appearance energies (AE) and Wannier exponents (p), as obtained for the main Rcarvone cations formed in the electron impact fragmentation process. Corresponding NIST results [28], in eV, are also listed in bold where possible.

\begin{tabular}{|c|c|c|c|c|}
\hline $\mathrm{M}(\mathrm{amu})$ & Cation & $\mathrm{AE}(\mathrm{eV})$ & $\mathrm{p}$ & NIST [28] \\
\hline 14 & $\mathrm{CH}_{2}^{+}$ & $15.34 \pm 0.54$ & $1.68 \pm 0.40$ & \\
\hline 16 & $\mathrm{O}^{+}$ & $14.16 \pm 0.36$ & $1.16 \pm 0.23$ & \\
\hline 26 & $\mathrm{C}_{2} \mathrm{H}_{2}^{+}$ & $11.67 \pm 0.14$ & $1.44 \pm 0.09$ & \\
\hline \multirow[t]{2}{*}{28} & $\mathrm{C}_{2} \mathrm{H}_{4}^{+}$and $\mathrm{CO}^{+}$ & $12.30 \pm 0.55$ & $1.79 \pm 0.32$ & \\
\hline & & $14.58 \pm 0.21$ & $1.01 \pm 0.17$ & \\
\hline \multirow[t]{2}{*}{29} & $\mathrm{C}_{2} \mathrm{H}_{5}^{+}$ & $12.04 \pm 1.50$ & $2.79 \pm 0.75$ & \\
\hline & $\mathrm{CHO}^{+}$ & $14.93 \pm 1.09$ & $1.26 \pm 0.88$ & \\
\hline 31 & $\mathrm{CH}_{3} \mathrm{O}^{+}$ & $11.97 \pm 0.69$ & $1.88 \pm 0.35$ & \\
\hline \multirow[t]{2}{*}{39} & $\mathrm{C}_{3} \mathrm{H}_{3}^{+}$(2 isomers) & $10.83 \pm 0.09$ & $3.07 \pm 0.51$ & \\
\hline & & $15.61 \pm 0.28$ & $2.34 \pm 0.15$ & \\
\hline 40 & $\mathrm{C}_{3} \mathrm{H}_{4}^{+}$ & $10.63 \pm 0.26$ & $1.57 \pm 0.07$ & \\
\hline \multirow[t]{2}{*}{41} & $\mathrm{C}_{2} \mathrm{HO}^{+}$and $\mathrm{C}_{3} \mathrm{H}_{5}^{+}$ & $12.56 \pm 0.50$ & $1.35 \pm 0.62$ & \\
\hline & & $14.82 \pm 0.35$ & $1.20 \pm 0.25$ & \\
\hline 42 & $\mathrm{C}_{2} \mathrm{H}_{2} \mathrm{O}^{+}$ & $10.32 \pm 0.35$ & $2.31 \pm 0.24$ & \\
\hline 43 & $\mathrm{C}_{2} \mathrm{H}_{3} \mathrm{O}^{+}$ & $11.99 \pm 0.39$ & $2.08 \pm 0.29$ & \\
\hline 45 & $\mathrm{C}_{2} \mathrm{H}_{5} \mathrm{O}^{+}$ & $11.99 \pm 0.31$ & $2.03 \pm 0.20$ & \\
\hline 52 & $\mathrm{C}_{4} \mathrm{H}_{4}^{+}$ & $10.68 \pm 0.40$ & $1.15 \pm 0.11$ & \\
\hline 53 & $\mathrm{C}_{4} \mathrm{H}_{5}^{+}$ & $12.52 \pm 0.41$ & $2.39 \pm 0.39$ & \\
\hline 54 & $\mathrm{C}_{4} \mathrm{H}_{6}^{+}$ & $13.81 \pm 0.19$ & $1.91 \pm 0.17$ & \\
\hline 55 & $\mathrm{C}_{4} \mathrm{H}_{7}^{+}$ & $12.67 \pm 0.23$ & $2.44 \pm 0.17$ & \\
\hline 58 & $\mathrm{C}_{3} \mathrm{H}_{6} \mathrm{O}^{+}$ & $10.01 \pm 0.17$ & $1.11 \pm 0.13$ & \\
\hline 60 & $\mathrm{C}_{3} \mathrm{H}_{8} \mathrm{O}^{+}$ & $10.62 \pm 0.24$ & $1.47 \pm 0.17$ & \\
\hline 65 & $\mathrm{C}_{5} \mathrm{H}_{5}^{+}$ & $15.31 \pm 0.21$ & $2.21 \pm 0.07$ & \\
\hline 67 & $\mathrm{C}_{5} \mathrm{H}_{7}^{+}$ & $12.16 \pm 0.20$ & $2.49 \pm 0.13$ & \\
\hline 69 & $\mathrm{C}_{5} \mathrm{H}_{9}^{+}$ & $10.94 \pm 0.19$ & $2.54 \pm 0.16$ & \\
\hline 77 & $\mathrm{C}_{6} \mathrm{H}_{5}^{+}$ & $13.12 \pm 0.34$ & $2.95 \pm 0.26$ & \\
\hline 79 & $\mathrm{C}_{6} \mathrm{H}_{7}^{+}$ & $11.13 \pm 0.27$ & $3.09 \pm 0.27$ & \\
\hline 80 & $\mathrm{C}_{5} \mathrm{H}_{4} \mathrm{O}^{+}$ & $9.63 \pm 0.11$ & $1.89 \pm 0.11$ & \\
\hline 82 & $\mathrm{C}_{5} \mathrm{H}_{6} \mathrm{O}^{+}$ & $10.85 \pm 0.15$ & $1.97 \pm 0.13$ & \\
\hline 83 & $\mathrm{C}_{5} \mathrm{H}_{7} \mathrm{O}^{+}$ & $10.90 \pm 0.18$ & $2.63 \pm 0.16$ & \\
\hline 91 & $\mathrm{C}_{7} \mathrm{H}_{7}^{+}$or $\mathrm{C}_{6} \mathrm{H}_{3} \mathrm{O}^{+}$ & $10.83 \pm 0.37$ & $3.22 \pm 0.29$ & \\
\hline 92 & $\mathrm{C}_{7} \mathrm{H}_{8}^{+}$or $\mathrm{C}_{6} \mathrm{H}_{4} \mathrm{O}^{+}$ & $9.87 \pm 0.07$ & $1.55 \pm 0.06$ & \\
\hline 93 & $\mathrm{C}_{6} \mathrm{H}_{5} \mathrm{O}^{+}$ & $10.83 \pm 0.23$ & $2.09 \pm 0.22$ & \\
\hline 94 & $\mathrm{C}_{6} \mathrm{H}_{6} \mathrm{O}^{+}$ & $9.72 \pm 0.14$ & $2.01 \pm 0.15$ & \\
\hline 106 & $\mathrm{C}_{7} \mathrm{H}_{6} \mathrm{O}^{+}$ & $9.56 \pm 0.05$ & $1.59 \pm 0.05$ & \\
\hline 107 & $\mathrm{C}_{7} \mathrm{H}_{7} \mathrm{O}^{+}$ & $9.35 \pm 0.07$ & $1.95 \pm 0.06$ & \\
\hline 108 & $\mathrm{C}_{7} \mathrm{H}_{8} \mathrm{O}^{+}$ & $10.20 \pm 0.08$ & $1.46 \pm 0.07$ & \\
\hline 135 & $\mathrm{C}_{9} \mathrm{H}_{11} \mathrm{O}^{+}$ & $10.27 \pm 0.34$ & $1.41 \pm 0.24$ & 10.1 \\
\hline 150 & $\mathrm{C}_{10} \mathrm{H}_{14} \mathrm{O}^{+}$ & $9.49 \pm 0.07$ & $1.36 \pm 0.07$ & 9.77 \\
\hline
\end{tabular}

cations, observed at higher masses (130-134 amu). Surprisingly, this cation was not observed by Castilho et al. [18], at lower photon energies using the PES - He I lamp technique or by synchrotron tunable light at $275 \mathrm{eV}$ and $310 \mathrm{eV}$. However, they registered this cation $\left(\mathrm{O}^{+}\right)$ around the $\mathrm{O} 1 \mathrm{~s}$ edge $(536 \mathrm{eV})$, suggesting that its origin would be the result of a site-selective process in the fragmentation of a core-excited molecule, a fact also supported by Eberhardt et al. [33]. The formation of $\mathrm{O}^{+}$could, in principle, also come from the fragmentation of the water contaminant, but it is certainly produced together with the $\mathrm{C}_{10} \mathrm{H}_{\mathrm{n}}^{+}$cations.

We also registered in our MS the presence of the $\mathrm{C}^{+}, \mathrm{CH}^{+}, \mathrm{CH}_{2}^{+}$ and $\mathrm{CH}_{3}^{+}$cations, for masses in the range of $12-15 \mathrm{amu}$, and $\mathrm{H}^{+}$and $\mathrm{H}_{2}^{+}$for masses of 1 amu and 2 amu respectively, arising from the fragmentation of R-carvone, with the complementary cations listed in Table 1, and also due to successive fragmentation processes. The formation of the cations $\mathrm{C}^{+}(\mathrm{m}=12 \mathrm{amu}), \mathrm{O}^{+}(\mathrm{m}=16 \mathrm{amu})$ and $\mathrm{H}^{+}$ $(\mathrm{m}=1 \mathrm{amu})$ is evidence for the atomization of the molecular skeleton. Moreover, the observation of the cations $\mathrm{H}_{2}^{+}$and $\mathrm{H}_{2} \mathrm{O}^{+}$, among others in our spectrum, clearly illustrates the presence of molecular rearrangement processes in the fragmentation of $\mathrm{R}$ carvone.

\subsection{Appearance and ionization energies}

In this work the R-carvone first Ionization Energy (IE), as well as 

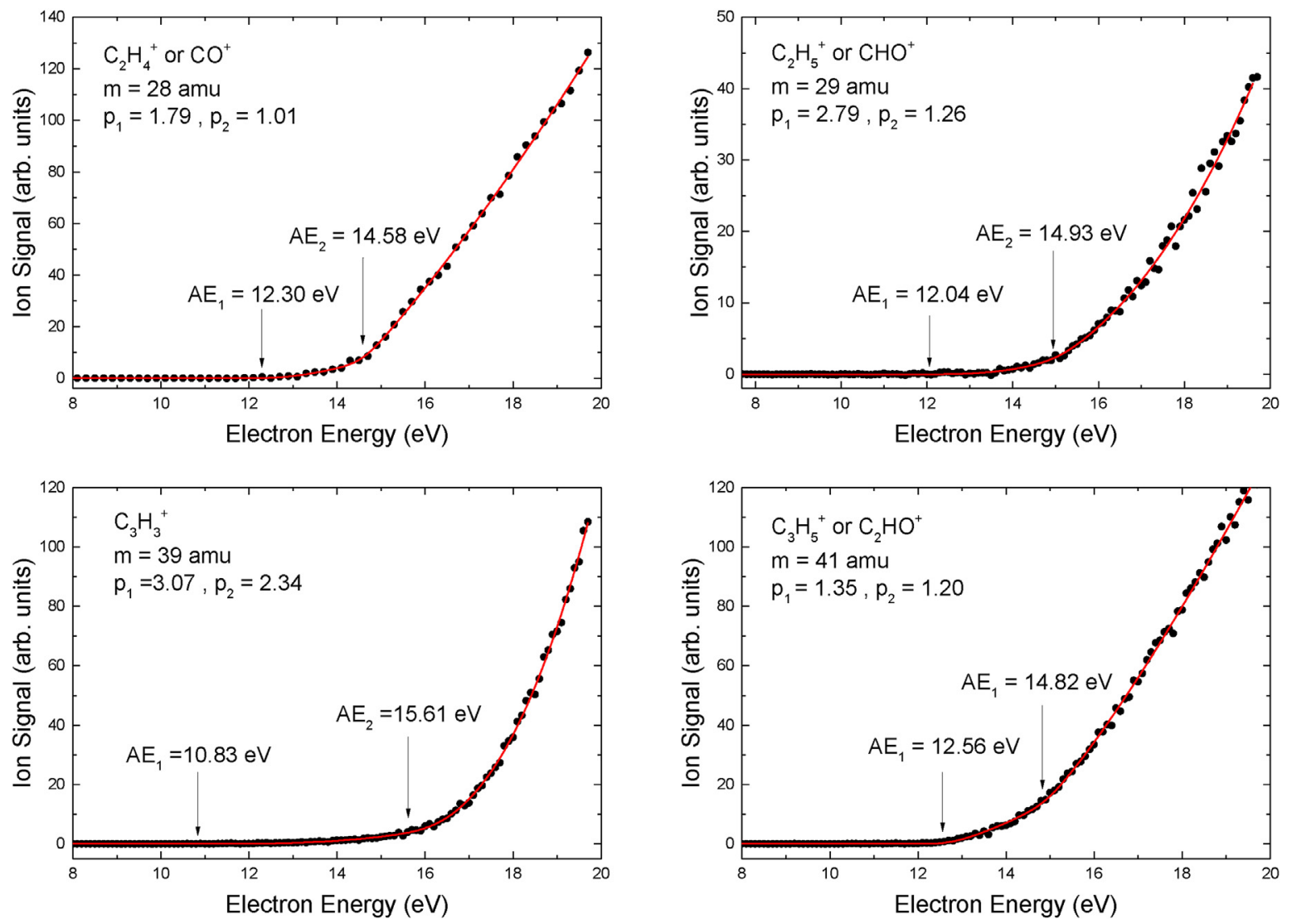

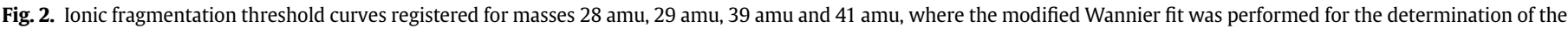

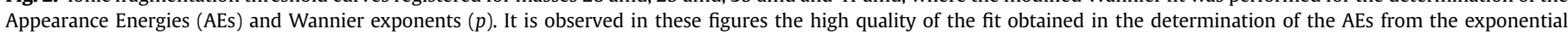
function in equation (3).

the ionic energy formation thresholds (Appearance Energies - AEs) were experimentally determined. While the IE is defined as the lowest energy required to remove an electron from a molecule in its ground state, the $\mathrm{AE}$ is the minimum energy required to induce a specific ionic fragmentation product, which involves fragmentation and ionization of the molecule. Accurate determination and experimental interpretation of the IE and $\mathrm{AE}$ fragmentation thresholds is a major challenge, given the occasional low intensities of the ionic signal involved [34,35]. A theoretical model that seeks to predict these values and is widely accepted in the scientific community, although its construction is semi-classical in nature, is Wannier's Law [36]. This formulation was originally proposed for the impact of electrons on atomic hydrogen, but in more recent years has been employed by many researchers to analyse many species. Fiegele et al. (2000) [37] extended this model to collisions of more complex multi-body systems, such as collisions of electrons with molecules. In their model the extended Wannier's Law is applied to a small region of energy, close to the expected value of the $\mathrm{AE}$, which can be observed in the ionic fragmentation (or ionization) threshold curves for a given product ion. A Wannier type function, $f(E)$, is used to fit the experimental ionization results in the cation production threshold range, to determine both Wannier's $\mathrm{AE}$ and $p$-exponent. That function can be written as follows [37,38]:
$f(E)=\left\{\begin{array}{cc}0 & ; \quad E<A E \\ c(E-A E)^{p} & ; \quad E \geq A E\end{array}\right.$

where $E$ is the electron impact energy and $c$ a scaling factor.

In this extended model, it is necessary to take into account the finite energy resolution of the electrons incident on the target [39]. Considering that the energy distribution of those electrons is a zero-centered Gaussian function, $g(E)$, it may be described by equation (2):

$g(E)=\frac{1}{\sqrt{2 \pi} \sigma} e^{-\left(\frac{E^{2}}{2 \sigma^{2}}\right)}$

where $\sigma$ is the standard deviation and $E$ is the impact energy $[38,40]$. Thus, the electron energy distribution (equation (2)) convoluted with the Wannier function (equation (1)) gives us formula (3) to be used to determine the IE or AEs from our measured ion yield curves:

$(g * f)(E)=\int_{A E}^{+\infty} e^{-\left(\frac{\left(E-E_{0}\right)^{2}}{2 \sigma^{2}}\right)}\left[A\left(E_{0}-A E\right)^{p}\right] d E_{0}$ 

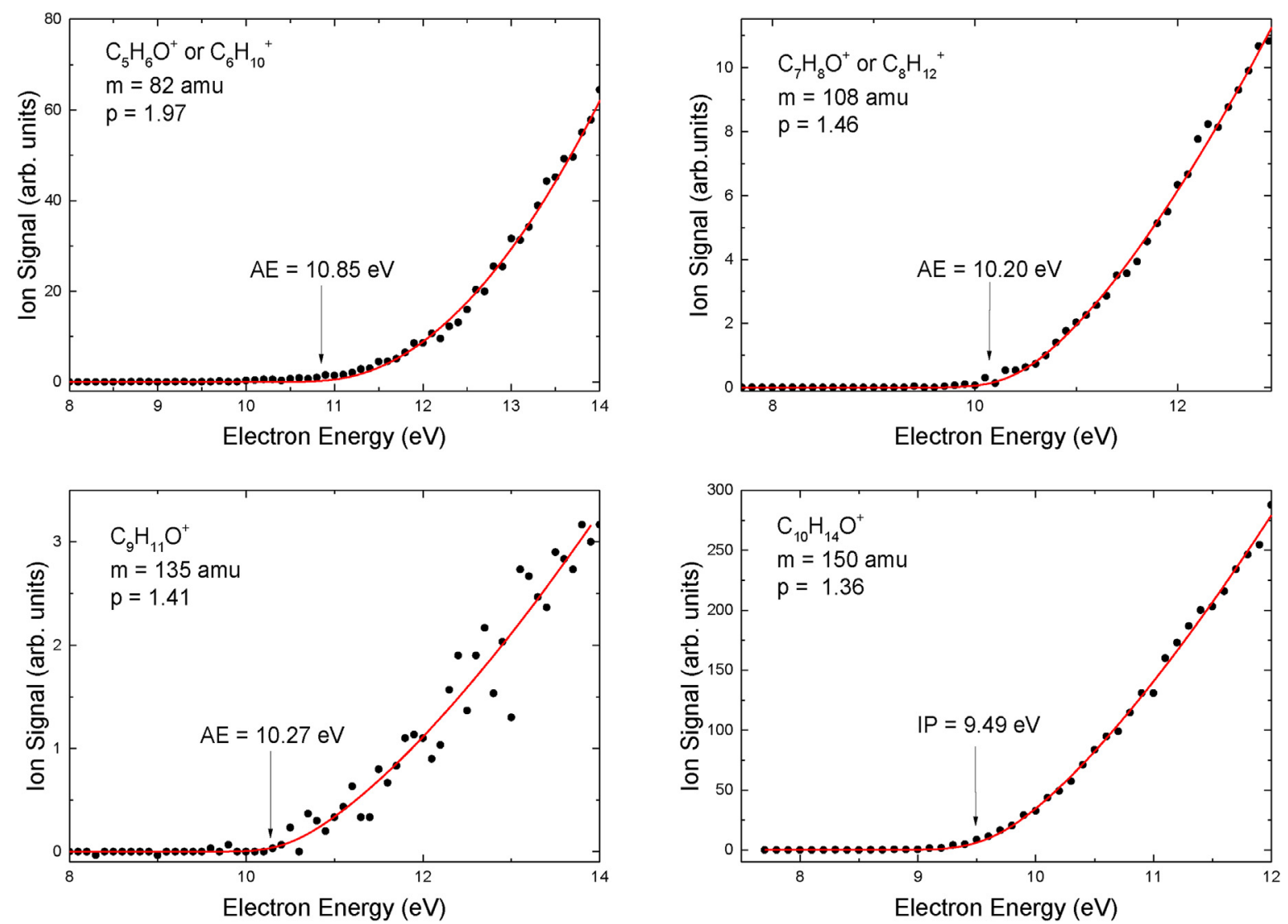

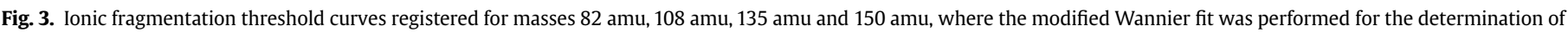
the Appearance Energies (AEs) and Wannier exponents $(p)$.

with the energy dispersion of the electrons, $\Delta E$ (full-width-halfmaximum - FWHM), of the incident electron beam:

$$
\Delta E=2 \sigma \sqrt{2 \ln 2} \approx 2.355 \sigma
$$

The convolution of equations (1) and (2) was undertaken in this work by nonlinear adjustment using the Marquardt-Levenberg algorithm. After fitting formula (3) to the experimental data, i.e. to the ionic fragmentation (or ionization) curves for near threshold impact energies, the values of the AEs (or IE) and Wannier's exponent $p$ were obtained.

The experimental acquisition of the ionic fragmentation threshold curves, as well as the respective residual gas or background curves, were performed by fixing the mass of the ionic fragment to be studied and by varying the electron impact energy in steps of $0.1 \mathrm{eV}$ around the region of their thresholds. The fragmentation curves used to obtain the $\mathrm{AE}$ and $p$ values, for a specific cation, were generated by averaging at least ten individual signal curves and then subtracting from that the average of the background (residual) signal. The nominal energy scale of these curves was calibrated against the Argon ionization threshold curve. Argon, besides having a well-known IP (15.759 eV) [41], also has a wellestablished $p$ value of 1.35 [37]. By setting $p=1.35$ in the modified Wannier fit to our experimental Argon ionization threshold curve, we obtained an $\mathrm{IP}_{\mathrm{Ar}}=16.06 \mathrm{eV}$ and $\sigma=0.28 \mathrm{eV}$. Hence the correction needed to calibrate our nominal energy scale is manifest from that result. In addition, by applying the generated value of $\sigma$ in equation (4), we estimated the energy resolution $\Delta \mathrm{E}$ of the incident electrons of our apparatus to be equal to $\sim 660 \mathrm{meV}$. That value of $\sigma$ $(0.28 \mathrm{eV})$ was used throughout all the subsequent determinations of the AEs and p's for the R-carvone cations we studied in this work.

Thirty-five fragmentation threshold curves, related to the most intense cations registered in our R-carvone mass spectrum, were recorded. Analyses of these results subsequently provided $38 \mathrm{AE}$ and $p$ values and one ionization energy (IE) for $M$, as shown in Table 2.

In our Figs. 2 and 3 we show the ionic fragmentation threshold curves for some of the cations listed in Table 2, together with the Wannier's Law fit and the derived $\mathrm{AE}$ and $p$ results. The values of the AE's and p's produced in this work, to the best of our knowledge, are being presented for the first time to the scientific community. The only exceptions to this general claim are for masses 135 amu and $150 \mathrm{amu}$, which have been reported previously in the NIST Standard Reference Database [28].

The 28 amu peak in the R-carvone mass spectrum may have been formed due to the contribution of two different molecular fragments with the same mass value, namely the ethylene $\left(\mathrm{C}_{2} \mathrm{H}_{4}^{+}\right)$ and carbon monoxide $\left(\mathrm{CO}^{+}\right)$cations. This statement is supported by our fit of the modified Wannier's Law to the experimental ionic fragmentation threshold curve (Fig. 2), where threshold energies from the formation of two cations were found at $\mathrm{AE}_{1}=12.30 \mathrm{eV}$ and $\mathrm{AE}_{2}=14.58 \mathrm{eV}$. Note, however, that it is not possible to assign which cation is associated with each energy. Similarly, for the mass at $29 \mathrm{amu}$, two $\mathrm{AE}$ values were found, $\mathrm{AE}_{1}=12.04 \mathrm{eV}$ and $\mathrm{AE}_{2}=14.93 \mathrm{eV}$, corresponding to the production of the ethyl $\left(\mathrm{C}_{2} \mathrm{H}_{5}^{+}\right)$ and $\mathrm{CHO}^{+}$cations. Two different AEs $\left(\mathrm{AE}_{1}=10.83 \mathrm{eV}\right.$ and $\mathrm{AE}_{2}=15.61 \mathrm{eV}$ ) were also determined at mass $39 \mathrm{amu}$ (Fig. 2), however in this case they are due to the formation of two isomers of the $\mathrm{C}_{3} \mathrm{H}_{3}^{+}$cation. Higher values of $p$ may point to a superposition of several ionic fragmentation channels for a given ionic mass, and 
both values for $p$ found at 39 amu $\left(p_{1}=3.07\right.$ and $p_{2}=2.34$, corresponding to $A E_{1}$ and $A E_{2}$ ) may indicate the contribution of more than one fragmentation pathway [37] in the $\mathrm{C}_{3} \mathrm{H}_{3}^{+}$formation. For example, the fragmentation diagrams (a) and (b) of Fig. 4, present the formation of the $\mathrm{C}_{3} \mathrm{H}_{3}^{+}$cation through different mechanisms. In (Fig. 4a) the $\mathrm{C}_{3} \mathrm{H}_{3}^{+}$cation, for which we determined an $\mathrm{AE}=15.61 \mathrm{eV}$, is produced through the loss of the $\mathrm{C}_{7} \mathrm{H}_{9} \mathrm{O}(\mathrm{m}=109$ amu) moiety from $\mathrm{M}$, forming the $\mathrm{C}_{3} \mathrm{H}_{5}^{+}$(41 amu) cation, which in turn subsequently loses two $\mathrm{H}$ atoms. An alternative path shown in Fig. 4b involves firstly a retro Diels-Alder reaction, producing the $\mathrm{C}_{5} \mathrm{H}_{8}$ moiety and the $\mathrm{C}_{5} \mathrm{H}_{6} \mathrm{O}^{+}(\mathrm{m}=82 \mathrm{amu})$ cation. The $\mathrm{C}_{5} \mathrm{H}_{6} \mathrm{O}^{+}$ cation next loses sequentially the $\mathrm{CO}$ species, forming a $\mathrm{C}_{4} \mathrm{H}_{6}^{+}$ cation, which further fragments by losing a methyl radical to form the $\mathrm{C}_{3} \mathrm{H}_{3}^{+}(\mathrm{m} / \mathrm{z}=39 \mathrm{amu})$ cation, whose $\mathrm{AE}$ we postulate to be $\mathrm{AE}_{1}=10.83 \mathrm{eV}$. The two $\mathrm{AE}$ values found for the production of the $\mathrm{C}_{3} \mathrm{H}_{3}^{+}$cations, through mechanisms (Fig. 4a) and (Fig. 4b), are very distinct, thus suggesting the formation of two different isomers. Note that, in the second fragmentation path (Fig. 4b), the AE found for the $\mathrm{C}_{4} \mathrm{H}_{6}^{+}$(54 amu) ion-formation is $13.81 \pm 0.19 \mathrm{eV}$, which is substantially higher compared to the AEs found for the parent cation $\left(\mathrm{C}_{5} \mathrm{H}_{8}^{+}\right)$, as well as the $\mathrm{C}_{3} \mathrm{H}_{3}^{+}$isomer. This suggests that these cations $\left(\mathrm{C}_{5} \mathrm{H}_{8}^{+}\right.$and the $\mathrm{C}_{3} \mathrm{H}_{3}^{+}$isomers) might also be formed through different mechanisms, to those shown in Fig. $4 \mathrm{~b}$, which is consistent with the higher values of $p$ found.

For the mass at 41 amu, we tentatively assigned the $\mathrm{AE}_{1}=12.56 \mathrm{eV}$ and $\mathrm{AE}_{2}=14.82 \mathrm{eV}$, shown in Fig. 2, with the formation of the $\mathrm{C}_{2} \mathrm{HO}^{+}$and $\mathrm{C}_{3} \mathrm{H}_{5}^{+}$cations, respectively. Considering the fragmentation mechanism shown in Fig. 4a, we assign the $\mathrm{AE}_{2}=14.82 \mathrm{eV}$ to the threshold energy for $\mathrm{C}_{3} \mathrm{H}_{5}^{+}$cation formation, given the time involved in the successive fragmentation of R-carvone and the acquisition mode used to record the ionic fragmentation threshold curves of the formed cations. It then follows that $\mathrm{AE}_{1}=12.30 \mathrm{eV}$, would correspond to the $\mathrm{C}_{2} \mathrm{HO}^{+}$cation formation. Each fragmentation mechanism shown in Fig. 4c-e, has AEs which are very similar (or equal, considering their respective errors) in all the steps. This similarity of the AEs here is expected, as mentioned before, considering the time of the successive fragmentations.

For the most abundant peak in our mass spectrum, corresponding to the mass at $82 \mathrm{amu}$ and assigned to the formation of the $\mathrm{C}_{5} \mathrm{H}_{6} \mathrm{O}^{+}$cation [18], we found an $\mathrm{AE}=10.85 \pm 0.15 \mathrm{eV}$ and a $p=1.97 \pm 0.13$ (see Fig. 3 ). This $\mathrm{AE}$ is in excellent agreement with the value of $10.85 \pm 0.1 \mathrm{eV}$ found by Wang et al. [42], in their investigation of the ionic fragmentation of the methyl methacrylate $\left(\mathrm{C}_{5} \mathrm{H}_{8} \mathrm{O}_{2}\right)$ molecule. Based on the Wang et al. [39] results, we can infer that our value of the $\mathrm{AE}=10.85 \pm 0.15 \mathrm{eV}$ is related to the sequential loss of two $\mathrm{H}$ atoms from the $\mathrm{C}_{5} \mathrm{H}_{8} \mathrm{O}^{+}$cation, as pointed out before. An alternative route for the formation of the $\mathrm{C}_{5} \mathrm{H}_{6} \mathrm{O}^{+}$ $(\mathrm{m}=82 \mathrm{amu})$ cation is through the retro Diels-Alder reaction. This is described in the mechanism of Fig. $4 \mathrm{~b}$, where we subsequently find an $\mathrm{AE}$ at around $13.81 \mathrm{eV}$ associated with the formation of the $\mathrm{C}_{4} \mathrm{H}_{6}^{+}$cation. The high value of $p$ found $(1.97 \pm 0.13)$ for the formation of the $\mathrm{C}_{5} \mathrm{H}_{6} \mathrm{O}^{+}$species corroborates the possibility of more

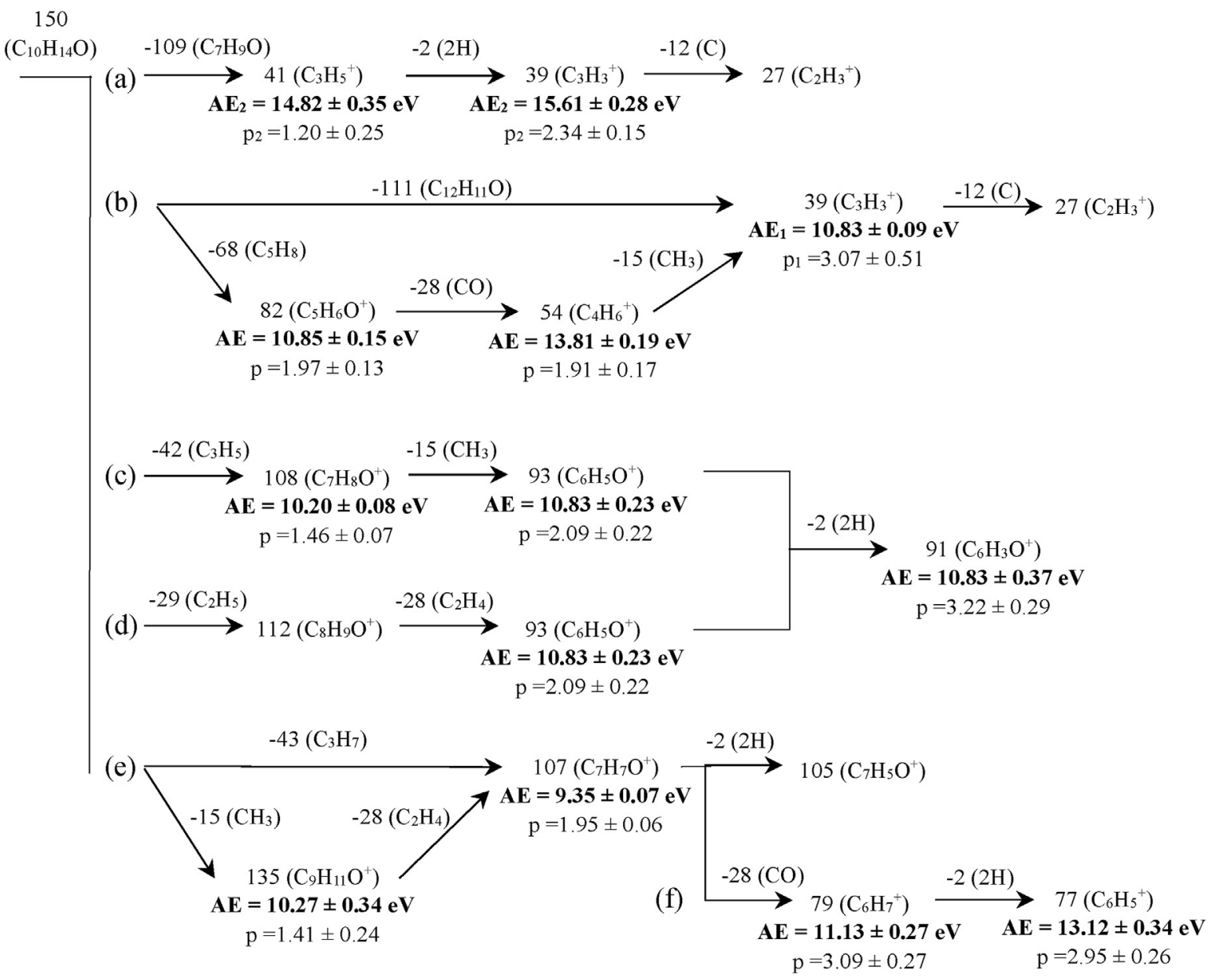

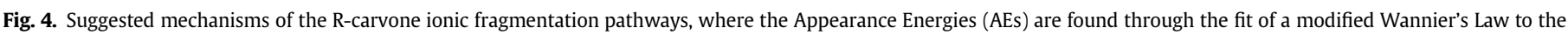
relevant ionic fragmentation threshold curves of the studied ions being highlighted. 
than one fragmentation pathway leading to $\mathrm{C}_{5} \mathrm{H}_{6} \mathrm{O}^{+}(\mathrm{m}=82 \mathrm{amu})$ cation formation. Clearly, however, further studies of these mechanisms are necessary for a more quantitative assignment to be made.

For the production of the $\mathrm{C}_{9} \mathrm{H}_{11} \mathrm{O}^{+}(\mathrm{m}=135 \mathrm{amu})$ cation, with $\mathrm{AE}=10.27 \pm 0.34 \mathrm{eV}$ as shown in Fig. 3, we found our result to be in excellent agreement with the value of $10.1 \mathrm{eV}$ reported by Bunau et al. [28,29]. We also found for the parent cation $\left(\mathrm{M}^{+}\right)$of R-carvone $\left(\mathrm{C}_{10} \mathrm{H}_{14} \mathrm{O}^{+}\right)$an IP $=9.49 \pm 0.30 \mathrm{eV}$, as is shown in Fig. 3, which is in quite good agreement with the accepted ionization energy of
$9.77 \mathrm{eV}[28,29]$ obtained using the electron impact ionization method. We note, however, that these IP's are higher in value compared to that of $8.7 \pm 0.05 \mathrm{eV}$, as obtained through the Threshold Photoelectron Spectroscopy (TPES) technique reported by Ref. [19].

Some molecular structural mechanisms for R-carvone ionic fragmentation are proposed in Fig. 5. In these mechanisms, the cations are produced from a breakage of the bonds between saturated and unsaturated carbons, with the resultant AEs being very similar in value. Fig. 5a shows a mechanism proposed by Castilho

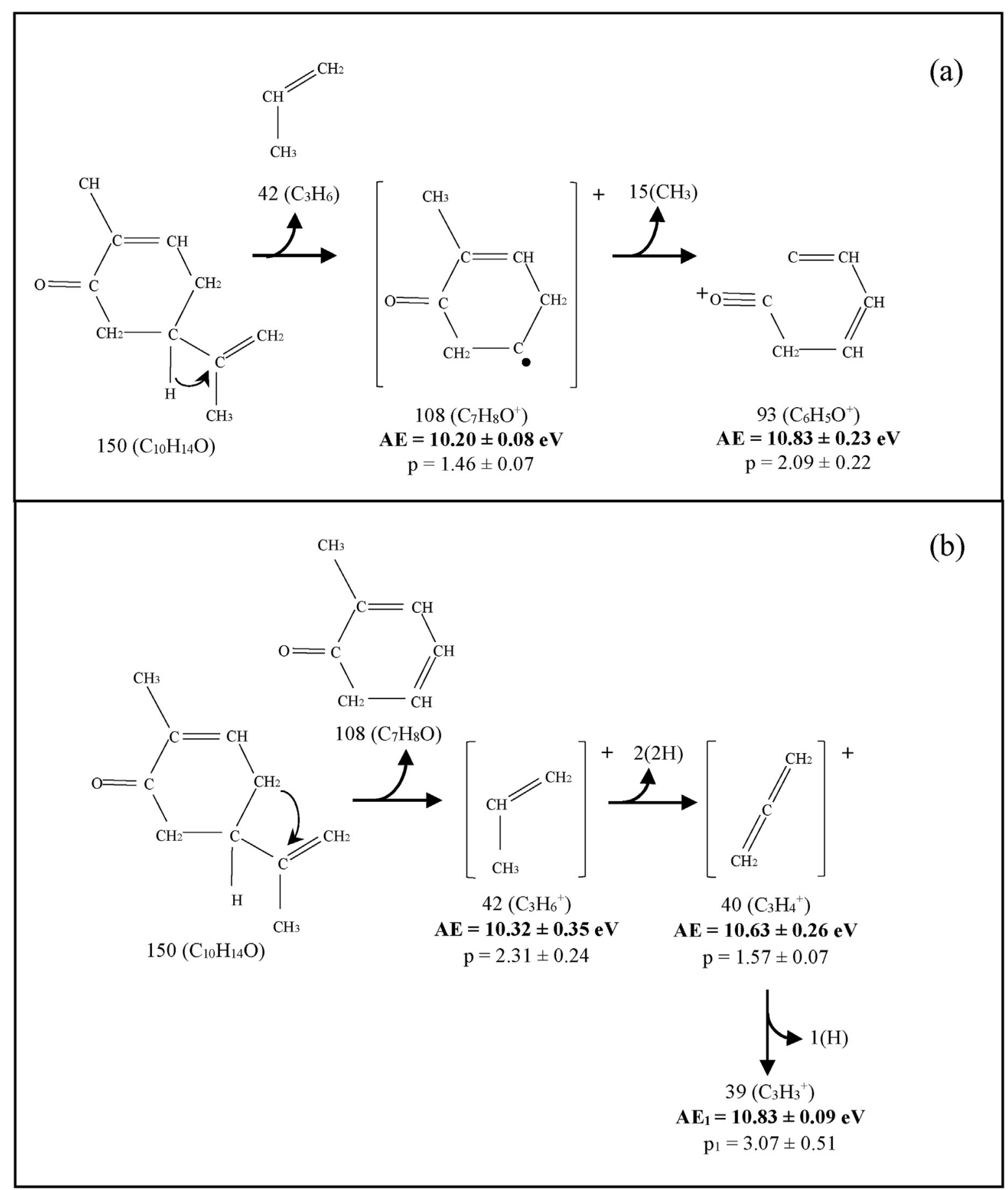

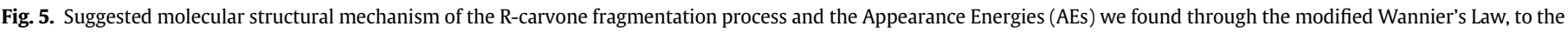
ionic fragmentation threshold curves of the studied ions. 
et al. [18], and corroborated by our AE results $(10.20 \pm 0.08 \mathrm{eV}$ for $\mathrm{C}_{7} \mathrm{H}_{8} \mathrm{O}^{+}$and $10.83 \pm 0.23 \mathrm{eV}$ for $\mathrm{C}_{6} \mathrm{H}_{5} \mathrm{O}^{+}$), which are very similar. In this pathway the R-carvone fragments are produced by the breakage of the isopropenyl moiety, forming the $\mathrm{C}_{7} \mathrm{H}_{8} \mathrm{O}^{+}(\mathrm{m}=108$ amu) ion, followed by the loss of a methyl radical, producing the $\mathrm{C}_{6} \mathrm{H}_{5} \mathrm{O}^{+}(\mathrm{m}=93)$ cation.

Fig. $5 \mathrm{~b}$ shows an alternative pathway for the ionic fragmentation of R-carvone, in this case where loss of a $\mathrm{C}_{7} \mathrm{H}_{8} \mathrm{O}(\mathrm{m}=108 \mathrm{amu})$ moiety is observed in the first step. The loss of this moiety from $\mathrm{M}$ results in the formation of the isopropenyl cation $\left(\mathrm{C}_{3} \mathrm{H}_{6} \mathrm{O}^{+}, \mathrm{m}=42\right.$ amu) with its $\mathrm{AE}$ found at $10.32 \mathrm{eV}$, which is very close to the observed value from the mechanism shown in Fig. 5a. This suggests that both the fragmentation mechanisms of Fig. 5 (a) and (b) are plausible. The resultant $\mathrm{C}_{3} \mathrm{H}_{6}^{+}$cation subsequently loses two $\mathrm{H}$ atoms, producing the $\mathrm{C}_{3} \mathrm{H}_{4}^{+}(\mathrm{m}=40 \mathrm{amu})$ ion with an $\mathrm{AE}=10.63 \mathrm{eV}$, which in turn loses another $\mathrm{H}$-atom to form the $\mathrm{C}_{3} \mathrm{H}_{3}^{+}(\mathrm{m}=39 \mathrm{amu})$ cation. The two AEs found for the formation of the $\mathrm{C}_{3} \mathrm{H}_{3}^{+}$( $\left.\mathrm{m}=39 \mathrm{amu}\right)$ cation are associated with two isomers, as pointed out before, the propargyl and the cyclopropenium cations. These isomers have different stabilities, according to the theoretical study reported by Hrouda et al. [43], who concluded that the cyclopropenium cation is more stable than the open-chain isomer propargyl.

\section{Conclusions}

The mass spectrum of R-carvone $\left(\mathrm{C}_{10} \mathrm{H}_{14} \mathrm{O}\right)$, recorded using $70 \mathrm{eV}$ electron impact energy, was reported and analysed in this work. This spectrum covered the region of masses from 1 to 151 amu with a resolution of $1 \mathrm{amu}$, registering some 103 peaks associated with single or multiple ionic fragmentation. This number of observed peaks is much higher than has been registered previously, using both low energy electron and photon excitation. The present R-carvone mass spectrum typically showed good agreement with that reported in the NIST Standard Reference Database [28], where the base peak was assigned to the formation of the $\mathrm{C}_{5} \mathrm{H}_{6} \mathrm{O}^{+}$cation with a mass of $82 \mathrm{amu}$. The assignment of the other observed peaks, as well as their respective abundances relative to the base peak, were also reported in this work, some of them for the first time. We also measured the threshold ionic fragmentation curves for 38 of the most abundant ions observed in our mass spectrum, of which many of the derived AEs and $p$-exponents are being reported here for the first time. Exceptions to this claim are for masses at $135 \mathrm{amu}$ and $150 \mathrm{amu}$, which have been reported previously by NIST [28]. Based on the AE values obtained, we suggested several ionic fragmentation mechanisms for R-carvone under electron collision conditions. Some molecular structural ionic fragmentation mechanisms of R-carvone were also suggested, which are corroborated by the $\mathrm{AE}$ and $\mathrm{p}$ values found in this work. The present results may be very useful in various areas of research, which investigate and apply medicinal plants to the treatment of diseases using herbal therapies.

\section{Author contribution}

M.C.A. Lopes: Conceptualization, Project administration, Funding acquisition, Methodology, Investigation, Supervision, Writing review \& editing. W.A.D. Pires: Investigation, Formal analysis, Writing - original draft, Writing - review \& editing. R.A.A. Amorim: Investigation, Formal analysis, Writing - original draft, Writing review \& editing. A.C.P. Fernandes: Investigation, Writing - original draft. T.M. Casagrande: Investigation. D.B. Jones: Methodology, Writing - review \& editing, F. Blanco: Software, Resources, Validation. G. Garcia: Software, Resources, Validation. M.J. Brunger: Conceptualization, Methodology, Writing - review \& editing

\section{Declaration of competing interest}

The authors declare that they have no known competing financial interests or personal relationships that could have appeared to influence the work reported in this paper.

\section{Acknowledgements}

This work was supported by the Brazilian Conselho Nacional de Desenvolvimento Científico e Tecnológico (CNPq), Fundação de Amparo à Pesquisa do Estado de Minas Gerais (FAPEMIG) and FINEP. M.C.A.L. acknowledges financial support from CNPq, while W.A.D.P., A.C.P.F. and R.A.A.A. acknowledge their fellowships from CAPES and FAPEMIG. Some financial assistance from the Australian Research Council through grant \# DP180101655 is also noted. Finally, G. Garcia thanks the CSIC project LINKA20085.

\section{References}

[1] L. Gachkar, D. Yadegari, M.B. Rezaei, M. Taghizadeh, S.A. Astaneh, I. Rasooli, Food Chem. 10 (2007) 898.

[2] M. Oussalah, S. Caillet, S. Salmiéri, L. Saucier, M. Lacroix, J. Food Protect. 70 (2007) 901.

[3] I. Lampronti, A.M. Saab, R. Gambari, Int. J. Oncol. Res. 29 (2006) 989.

[4] T. Mihajilov-Krstev, D. Radnović, D. Kitić, V.S. Jovanović, V. Mitić, Z. StojanovićRadić, B. Zlatković, Cent. Eur. J. Biol. 9 (2014) 668.

[5] A.M. Saab, R. Gambari, G. Sacchetti, A. Guerrini, I. Lampronti, M. Tacchini, A. El Samrani, S. Medawar, H. Makhlouf, M. Tannoury, J. Abboud, M. Diab-Assaf, A. Kijjoa, R. Tundis, J. Aoun, T. Efferth, Nat. Prod. Res. 32 (2018) 1415.

[6] M.L. da Rocha, L.E.G. Oliveira, C.C.M. Patrício Santos, D.P. de Sousa, R.N. de Almeida, D.A.M. Araújo, J. Nat. Med. 67 (2013) 743.

[7] C.C.R. Carvalho, M.M.R. Fonseca, Food Chem. 95 (2006) 413.

[8] J.C. Gonçalves, F.S. Oliveira, R.B. Benedito, D.P. de Sousa, R.N. de Almeida, D.A. de Araújo, Biol. Pharm. Bull. 31 (2008) 1017.

[9] R.N. de Almeida, D.P. de Sousa Dp, F.F. Nóbrega, F.S. Claudino, D.A. Araújo, J.R. Leite, R. Mattei, Neurosci. Lett. 443 (2008) 51.

[10] G. Buchbauer, W. Jäger, A. Gruber H. Dietrich, Flavour Frag. J. 20. 6 (2005) 686.

[11] B.B. Aggarwal, W. Yuan W, S. Li, S.C. Gupta, Mol. Nutr. Food Res. 57 (2013) 1529.

[12] P. McGeady, D.L. Wansley, D.A. Logan, J. Nat. Prod. 65 (2002) 953.

[13] E. Alizadeh, L. Sanche, Chem. Rev. 112 (2012) 5578.

[14] A.G. Sanz, M.C. Fuss, A. Muñoz, F. Blanco, P. Limão-Vieira, M.J. Brunger, G. García, Int. J. Radiat. Biol. 88 (2012) 71.

[15] M.J. Brunger, K. Ratnavelu, S.J. Buckman, D.B. Jones, A. Muñoz, F. Blanco, G. García, Eur. Phys. J. D 70 (2016) 46.

[16] H. Tanaka, M.J. Brunger, L. Campbell, H. Kato, M. Hoshino, A.R.P. Rau, Rev. Mod. Phys. 88 (2016), 025004.

[17] M.J. Brunger, Int. Rev. Phys. Chem. 36 (2017) 333.

[18] R.B. de Castilho, C.V. Nunez, A.F. Lago, A.C.F. Santos, L.H. Coutinho, C.A. Lucas, S. Pilling, M.O. Silva-Moraes, G.G.B. de Souza, J. Electron Spectros. 192 (2014) 61.

[19] G.A. Garcia, L. Nahon, I. Powis, Int. J. Mass Spectrom. 225 (2003) 261.

[20] D.B. Jones, E. Ali, C.G. Ning, F.F. da Silva, O. Ingólfsson, M.C.A. Lopes, H.S. Chakraborty, D.H. Madison, M.J. Brunger, J. Chem. Phys. 151 (2019), 124306.

[21] K.L. Nixon, W.A.D. Pires, R.F.C. Neves, H.V. Duque, D.B. Jones, M.J. Brunger M.C.A. Lopes, Int. J. Mass Spectrom. 404 (2016) 48.

[22] W.A.D. Pires, K.L. Nixon, S. Ghosh, R.F.C. Neves, H.V. Duque, R.A.A. Amorim, D.B. Jones, F. Blanco, G. Garcia, M.J. Brunger, M.C.A. Lopes, Int. J. Mass Spectrom. 422 (2017) 32.

[23] W.A.D. Pires, K.L. Nixon, S. Ghosh, R.A.A. Amorim, R.F.C. Neves, H.V. Duque, D.G.M. da Silva, D.B. Jones, M.J. Brunger, M.C.A. Lopes, Int. J. Mass Spectrom. 430 (2018) 158.

[24] M.C.A. Lopes, W.A.D. Pires, K.L. Nixon, R.A.A. Amorim, D.G.M. Silva, A.C.P. Fernandes, S. Ghosh, D.B. Jones, L. Campbell, R.F.C. Neves, H.V. Duque, G. García, F. Blanco, M.J. Brunger, Eur. Phys. J. D 74 (2020) 88.

[25] N.V. Krasnov, A.F. Kuzmin, A.N. Arseniev, Scientific Instrumentation 21 (2011) 4. In Russian.

[26] V.B. Almazov, A.D. Andreeva, L.N. Gall, T.V. Pomozov, Scientific Instrumentation 22 (2012) 1. In Russian.

[27] J.E. Amoore, Chem. Senses and Flavour 4 (1979) 153.

[28] P.J. Linstrom, W.G. Mallard (Eds.), NIST Chemistry WebBook, NIST Standard Reference Database, 69th ed., National Institute of Standards and Technology, Gaithersburg, MD, 2001, 20899. http://webbook.nist.gov.

[29] G. von Bunau, G. Schade, K. Gollnick, Z. für Anal. Chem. 227 (1967) 173.

[30] Spectral database for organic compounds (SDBS). https://sdbs.db.aist.go.jp/ sdbs/cgi-bin/landingpage?sdbsno=2349.

[31] B.P. Tsai, J.H.D. Eland, Int. J. Mass Spectrom. Ion Process. 36 (1980) 143.

[32] R.G. Kingston, M. Guilhaus, A.G. Brenton, J.H. Beyon, Org. Mass Spectrom. 20 (1985) 406. 
[33] W. Eberhardt, T.K. Sham, R. Carr, S. Krummacher, M. Strongin, S.L. Weng, D. Wesner, Phys. Rev. Lett. 50 (1983) 1038

[34] D.L. Hildenbrand, Int. J. Mass Spectrom. 197 (2000) 237.

[35] H.M. Rosenstock, Int. J. Mass Spectrom. 20 (1976) 139.

[36] G.H. Wannier, Phys. Rev. 90 (1953) 817.

[37] T. Fiegele, G. Hanel, I. Torres, M. Lezius, T.D. Märk, J. Phys. B Atom. Mol. Opt. Phys. 33 (2000) 4263.

[38] S. Matt, O. Echt, R. Wörgötter, V. Grill, P. Scheier, C. Lifshitz, T.D. Märk, Chem. Phys, Lett. 264 (1997) 149.

[39] S. Ghosh, K.L. Nixon, W.A.D. Pires, R.A.A. Amorim, R.F. Neves, H.V. Duque,
D.G.M. da Silva, D.B. Jones, F. Blanco, G. Garcia, M.J. Brunger, M.C.A. Lopes, Int J. Mass Spectrom. 430 (2018) 44.

[40] E.O. Jesus, R. Costa Jr., in: Proceeding Series of the Brazilian Society of Computational and Applied Mathematics - XXXV, vol. 3, CNMAC, 2015. N.1.

[41] B. Gstir, S. Denifl, G. Hanel, M. Rümmele, T. Fiegele, P. Cicman, M. Stano, S. Matejcik, P. Scheier, K. Becker, A. Stamatovic, T.D. Märk, J. Phys. B Atom. Mol. Opt. Phys. 35 (2002) 2993.

[42] J. Wang, B. Yang, T.A. Cool, N. Hansen, Int. J. Mass Spectrom. 292 (2010) 14.

[43] V. Hrouda, P. Cársky, M. Ingr, Z. Chval, G.N. Sastry, T. Bally, J. Phys. Chem. 102 (1988) 9297. 